\title{
Rheological investigation of collagen, fibrinogen, and thrombin solutions for drop-on-demand 3D bioprinting $\dagger$
}

\author{
Hemanth Gudapati, ${ }^{a}$ Daniele Parisi, ${ }^{\mathrm{b}}$ Ralph H. Colby, ${ }^{* b, \mathrm{c}}$ and Ibrahim T. Ozbolat*a,c,d \\ ${ }^{a}$ Department of Engineering Science and Mechanics, The Pennsylvania State University, University Park, PA, \\ 16802. USA. E-mail: ito1@ @su.edu \\ ${ }^{b}$ Department of Materials Science and Engineering, The Pennsylvania State University, University Park, PA, 16802, \\ USA.E-mail: rhc@plmsc.psu.edu \\ 'Materials Research Institute, The Pennsylvania State University, University Park, PA, 16802, USA \\ ${ }^{\mathrm{d}}$ Huck Institutes of the Life Sciences, The Pennsylvania State University, University Park, PA, 16802, USA \\ $\dagger$ Electronic supplementary information (ESI) available.
}

\begin{abstract}
Collagen, fibrinogen, and thrombin proteins in aqueous buffer solutions are widely used as precursors of natural biopolymers for three-dimensional (3D) bioprinting applications. The proteins are sourced from animals and their quality may vary from batch to batch, inducing differences in the rheological properties of such solutions. In this work, we investigate the rheological response of collagen, fibrinogen, and thrombin protein solutions in bulk and at the solution/air interface. Interfacial rheological measurements show that fibrous collagen, fibrinogen and globular thrombin proteins adsorb and aggregate at the solution/air interface, forming a viscoelastic solid film at the interface. The viscoelastic film corrupts the bulk rheological measurements in rotational rheometers by contributing to an apparent yield stress, which increases the apparent bulk viscosity up to shear rates as high as $1000 \mathrm{~s}^{-1}$. The addition of a non-ionic surfactant, such as polysorbate 80 (PS80) in small amounts between 0.001 and $0.1 \mathrm{v} / \mathrm{v} \%$, prevents the formation of the interfacial layer, allowing the estimation of true bulk viscosity and viscoelastic properties of the solutions. The estimation of viscosity not only helps in identifying those protein solutions that are potentially printable with drop-on-demand (DOD) inkjet printing but also detects inconsistencies in flow behavior among the batches.
\end{abstract}




\section{Introduction}

Collagen is a fibrous protein and functions as extracellular matrix (ECM) in most mammalian tissues. Among several types (up to 28) of collagen, collagen type I is commonly used as a structural biomaterial in 3D bioprinting applications because of its biocompatible, biomimetic, and biodegradable properties. ${ }^{1-5}$ Similarly, fibrinogen is a fibrous protein of blood and the globular enzyme thrombin polymerizes it into a fibrous hydrogel, known as fibrin, promoting blood clotting and wound healing. ${ }^{6}$ Fibrin is commonly used as a functional biomaterial in $3 \mathrm{D}$ bioprinting applications to accelerate ECM deposition and vascularization. ${ }^{4,7}$ Drop-on-demand (DOD) inkjet printing accurately delivers small volumes ( $1-100$ picolitres) of fluids, inexpensively fabricating features at a high resolution of $\leq 100 \mu \mathrm{m}$ for structural and functional material applications. ${ }^{8,9}$ Drop-on-demand inkjet printing of collagen, fibrinogen, and thrombin proteins in aqueous buffer solutions is desired for 3D bioprinting applications to emulate native tissue physiology during the high-throughput fabrication of organ-on-chip devices and disease models. The formation of stable droplets of polymer and macromolecular solutions during DOD inkjet printing is a delicate interplay of inertial, viscous, elastic, and capillary forces. ${ }^{10,11}$ Hence, formation of droplets of protein solutions and spreading behavior of those droplets is controlled by the flow behavior of protein solutions.

Unfortunately, collagen, fibrinogen, and thrombin are sourced from animals and hence are expensive and their quality varies from batch to batch. The batch-to-batch quality variations affect the flow behavior of the solutions and mechanical properties of the polymerized biopolymers or protein hydrogels, affecting the outcome of 3D bioprinting applications. The conventional bulk rheology measurements of protein solutions with a cone-and-plate geometry are essential for understanding the flow behavior of those solutions and require very low sample volumes. The 
measurements also reveal valuable information about the quality of proteins through parameters such as intrinsic viscosity $([\eta]) .{ }^{12}$ However, globular proteins were previously shown to adsorb and aggregate at the air/water $(\mathrm{A} / \mathrm{W})$ interface of rheometry fixtures, corrupting the bulk viscosity measurements of those protein solutions by contributing an apparent yield stress. ${ }^{13-15}$

Proteins, in general, aggregate because of the self-association of native structures or the destabilization of their native structures in response to stresses such as mechanical stress, ionic charge, and hydrophobicity. ${ }^{14,16}$ It is not yet known whether the native proteins self-associate or the destabilized partially unfolded proteins form a nucleus, which further grows into an aggregate. ${ }^{17-19}$ The globular protein aggregates at the air/water interface often desorb from the interface because of mechanical disturbances and cause further aggregation in the bulk. ${ }^{20,21}$ In addition, the bulk aggregation of globular proteins increases during storage as well. ${ }^{22}$ Any adsorption or aggregation of collagen, fibrinogen, and thrombin at the air/water interface corrupts the bulk rheology measurements with conventional rotational rheometers. In addition, the surfaceinduced aggregation of those proteins has several physical and biological implications beyond DOD inkjet printing for tissue engineering and regenerative medicine applications. Such implications may include immunogenicity, ${ }^{23}$ reduced or no biological activity, ${ }^{19}$ poor alignment of fibrils of structural proteins (collagen), ${ }^{24}$ and inconsistent mechanical properties of protein hydrogels (fibrin) .

Although bulk rheology of type I collagen acidic solutions (at $\mathrm{pH} 2.5$ ) was previously investigated by Gobeaux et al. ${ }^{25}$, the influence of interfacial interactions on the bulk rheology measurements was not reported. Similarly, fibrinogen was shown to adsorb at the air/water interface. ${ }^{26,27}$ For example, Ariola et al..$^{27}$ investigated the interfacial adsorption of fibrinogen with interfacial rheology. However, those solutions were too dilute $\left(<25 \times 10^{-11} \mathrm{mg} / \mathrm{mL}\right)$ to have any 
significance for DOD inkjet printing and the influence of interfacial adsorption on the bulk rheology measurements was not reported. Moreover, the addition of a non-ionic surfactant such as polysorbate 80 (PS80) to globular protein solutions prevents the surface-induced aggregation and gives a good estimation of the true bulk viscosity of those solutions using the conventional rotational rheometers. ${ }^{14}$ The surfactant prevents the surface-induced aggregation of proteins by competitively adsorbing at the interface. The interactions between globular proteins and nonionic surfactants are generally very weak ${ }^{28-31}$ and polysorbate 80 , when added to water at a concentration of $\leq 10 \mathrm{mM}$, increases the viscosity of water only by $\leq 8 \% .^{32}$

The primary objective of this work is to gain a better understanding of the interfacial interactions of collagen, fibrinogen, thrombin proteins at the air/water interface of surfactant-free and surfactant-laden protein solutions and how those interactions affect the interfacial and bulk rheological properties. The secondary objective of this work is to accurately estimate the bulk viscosity and viscoelastic properties of protein solutions and the intrinsic viscosity $[\eta]$ and overlap concentration $\left(c^{*}\right)$ of the investigated proteins through steady and dynamic shear rheology measurements. This was achieved by means of addition of the surfactant polysorbate 80 to the protein solutions. In this work, the yield stress refers to the minimum shear stress at which a protein solution showing a solid-like response begins to flow like a liquid. Also, the aggregation of protein refers to the supra-monomeric assemblies formed due to reversible self-association, reversible clustering, and irreversible clustering of the protein monomers.

\section{Materials and methods}

\subsection{Protein solutions}


Collagen type I was extracted from tail tendon of 16-week-old rats (F344/DuCrl from Envigo) according to a previously published protocol. ${ }^{33} \mathrm{~A}$ stock collagen solution was prepared at a concentration of $6 \mathrm{mg} / \mathrm{mL}$ by dissolving the extracted freeze-dried collagen sponges in $0.02 \mathrm{~N}$ acetic acid (Sigma-Aldrich 695092) and was sterilized according to our previously published study. ${ }^{34}$ The sterilized stock solution was stored at $4{ }^{\circ} \mathrm{C}$ for future use. At the time of measurements, the stock collagen solution was neutralized at desired concentrations using sterile 10X phosphatebuffered saline solution (PBS, Corning 46-013-CM, pH 7.4), sterile $1 \mathrm{~N} \mathrm{NaOH}$ solution (SigmaAldrich 109137), and sterile deionized (DI) water according to Corning® Collagen I (cat. no. 354236) product specification sheet. The $\mathrm{NaOH}$ solution and DI water were sterilized using a 0.22 $\mu \mathrm{m}$ syringe filter (Sigma-Aldrich SLGPM33RS). The neutralized collagen solutions, when maintained at room temperature, were crosslinking within 5-15 min. As a result, the temperature of those solutions was maintained at $4{ }^{\circ} \mathrm{C}$ during measurements to prevent crosslinking.

Bovine fibrinogen protein crystals, isolated from bovine plasma (Sigma-Aldrich F8360), were dissolved in Dulbecco's phosphate-buffered saline solution (DPBS, Corning 20-031-CV, pH 7.4) to prepare a stock solution of $100 \mathrm{mg} / \mathrm{mL}$. Similarly, bovine thrombin protein powder, isolated from bovine plasma (Sigma-Aldrich T4648), was dissolved in DPBS to prepare a stock solution of $21.3 \mathrm{mg} / \mathrm{mL}$, which corresponded to an enzymatic activity of 1000 National Institute of Health units $/ \mathrm{ml}(\mathrm{U} / \mathrm{mL})$. The stock solutions of fibrinogen and thrombin were stored at $-30{ }^{\circ} \mathrm{C}$ to prevent their denaturation and loss of their biological activity. At the time of measurements, those stock solutions were diluted to desired concentrations using DPBS and were maintained at $25^{\circ} \mathrm{C}$. The isoelectric points $(\mathrm{pI})$ of collagen, fibrinogen, and thrombin are $7.5,{ }^{35} 5.8,{ }^{36-38}$ and $9.5,{ }^{39}$ respectively. As a result, collagen was roughly neutral in DPBS, fibrinogen was negatively charged in DPBS, and thrombin was positively charged in DPBS. In addition, the collagen molecule has a 
triple helix structure (length $300 \mathrm{~nm}$, diameter $1.6 \mathrm{~nm}$, and persistence length $14.5 \mathrm{~nm}$ ), ${ }^{40-42}$ fibrinogen molecule has a flexible structure (length $45 \mathrm{~nm}$, diameter $5 \mathrm{~nm}$, and persistence length $0.8 \mathrm{~nm}),{ }^{38,43}$ and thrombin molecule has a globular or ellipsoid structure $(4.5 \times 4.5 \times 5 \mathrm{~nm}){ }^{44}$

The surfactant-laden protein solutions were prepared by adding polysorbate 80 (SigmaAldrich P1754, CMC of $0.012 \mathrm{mM})^{45}$ to protein solutions at the time of measurements. The surfactant was added at a concentration of $0.001 \mathrm{v} / \mathrm{v} \%(0.012 \mathrm{mM})$ to collagen and thrombin solutions through successive dilutions to prevent the yield stress. The volume of PS80 required to prevent the yield stress increased with fibrinogen concentration. As a result, the surfactant was added at a concentration of $0.001-0.1 \mathrm{v} / \mathrm{v} \%(0.012-1.224 \mathrm{mM})$ to fibrinogen solutions through successive dilutions.

\subsection{Capillary viscometry experiments}

A Cannon-Ubbelohde semi-micro viscometer (Cannon Instrument Company) with a capillary diameter of $0.310 \mathrm{~mm}$ was used for measuring the viscosity of surfactant-free protein solutions. This viscometer has no air/water interface during the free downward efflux of samples and hence there was no interfacial contribution to the bulk viscosity of the samples. As a result, the viscosity data and the corresponding intrinsic viscosity $[\eta]$ and overlap concentration $c^{*}$ data were used as positive controls in this study. During measurements, $\sim 3 \mathrm{~mL}$ of samples was added to the viscometer which was placed in a circulating water bath. The efflux time of collagen samples was measured when their temperature reached $4 \pm 1{ }^{\circ} \mathrm{C}$ whereas the efflux time of fibrinogen and thrombin samples was measured when their temperature reached $25 \pm 0.5{ }^{\circ} \mathrm{C}$. In addition, the efflux time of each sample was measured three times and the average of those times was interpolated with the efflux time of the solvent to calculate the relative viscosity $\left(\eta_{r}\right)$ of the sample: 


$$
\mathrm{\eta}_{r}=\frac{\mathrm{\eta}}{\eta_{s}}
$$

where $\eta$ is the viscosity of the sample and $\eta_{s}$ is the viscosity of the solvent. The efflux time $(t)$ of the sample was controlled by its viscosity $\eta$ and density $(\rho)$ and the viscometer constant $\left(K_{v}\right)$ :

$$
t=\frac{\eta}{\rho K_{v}}
$$

Accordingly, the relative viscosity of the sample protein solution was approximated using the following relationship:

$$
\frac{t}{t_{s}}=\frac{\eta}{\eta_{s}}\left(\frac{\rho_{s}}{\rho}\right)=\eta_{r}\left(\frac{\rho_{s}}{\rho}\right) \approx \eta_{r}
$$

where $t_{s}$ and $\rho_{s}$ are flow time and density of the solvent, respectively.

\subsection{Rheology experiments}

A stress-controlled rheometer (Anton Paar MCR 302), equipped with a $50 \mathrm{~mm}$ diameter stainless steel cone and plate with a cone angle of $1^{\circ}$ and truncation gap of $103 \mu \mathrm{m}$, was used for measuring the bulk viscosity and the bulk dynamic storage modulus $\left(G^{\prime}\right)$ and loss modulus $\left(G^{\prime \prime}\right)$ of protein solutions. The bulk viscosity was averaged out using three different samples for each protein concentration. Each sample was $\sim 700 \mu \mathrm{l}$ and once loaded in the rheometer was initially presheared for $5 \mathrm{~min}$ at $60 \mathrm{~s}^{-1}$ to remove shear history effects associated with the sample preparation and loading steps. Afterwards, steady-shear measurements were performed with an initial measurement from 0 to $1000 \mathrm{~s}^{-1}$, followed by a final measurement from 1000 to $0 \mathrm{~s}^{-1}$. The moduli $G^{\prime}$ and $G^{\prime \prime}$ of protein solutions were obtained through dynamic shear-stain-amplitude sweeps (DSS). Three different samples were used for each protein concentration and the dynamic amplitude sweep of each sample, approximately $700 \mu 1$, was performed at a constant oscillation 
frequency $(\omega)$ of $1 \mathrm{rad} / \mathrm{s}$. The average values of the moduli from the three different measurements within the linear viscoelastic region are reported in Sections 3.2 and 3.3.

Similarly, the interfacial storage modulus $G^{\prime}$ and loss modulus $G^{\prime \prime}$ were obtained using a double-wall ring (DWR) geometry mounted on a hybrid strain-and-stress-controlled rheometer (DHR-3, TA Instruments) as described previously by Vandebril et al. ${ }^{46}$ The interfacial moduli of collagen solutions were obtained through dynamic amplitude sweeps at constant oscillation frequency of $1 \mathrm{rad} / \mathrm{s}$. Three different samples, each $\sim 10 \mathrm{~mL}$, were used for each collagen concentration and the measurements were performed immediately after loading because the collagen samples would crosslink within $5 \mathrm{~min}$ at temperatures higher than $4{ }^{\circ} \mathrm{C}$. To this end, the DWR trough was kept at $4{ }^{\circ} \mathrm{C}$ and the temperature was controlled by a Peltier plate and measured not only by the thermocouple of the Peltier unit, where the DWR trough sits, but also via an infrared (IR) thermometer. The average values of the moduli from the three different measurements within the linear viscoelastic region are reported in Sections 3.2.

The interfacial moduli of the fibrinogen solutions were obtained through dynamic frequency sweeps at a constant shear-strain amplitude of 0.008. A single sample of $\sim 10 \mathrm{~mL}$ was used for each fibrinogen concentration and the moduli were measured three times. The interfacial moduli of thrombin solutions were obtained through dynamic shear-strain amplitude sweeps at a constant oscillation frequency of $1 \mathrm{rad} / \mathrm{s}$. A single sample of approximately $10 \mathrm{~mL}$ was used for each thrombin concentration and the moduli were measured three times. For both fibrinogen and thrombin solutions, the first measurement was performed 10 min after loading the sample and the following measurements were performed 10 min after the completion of the previous measurement to allow sufficient time for the surface disturbances to dissipate. The average values of the moduli 
from the three different measurements within in the linear viscoelastic region are reported in Section 3.2.

\section{Results and discussion}

\subsection{Intrinsic viscosity of proteins in surfactant-free solutions}

Viscosity measurements, which were obtained with the Ubbelohde viscometer, allowed the estimation of the intrinsic viscosity $[\eta]$ and overlap concentration $c^{*}$ of proteins in surfactant-free solutions. The intrinsic viscosity $[\eta]$ generally quantifies the linear size of the protein monomers and was determined using the Huggins-Kraemer plots, based on the Huggins and Kraemer equations. The Huggins equation describes the concentration dependence of the reduced viscosity $\left(\eta_{\text {red }}\right)$ of protein solutions: ${ }^{47,48}$

$$
\eta_{\text {red }}=\frac{\eta_{s p}}{c}=[\eta]+k_{H}[\eta]^{2} c
$$

where $k_{H}$ is the Huggins coefficient and $\eta_{s p}=\left(\eta-\eta_{s}\right) / \eta_{s}$ is the specific viscosity of protein solutions. ${ }^{12}$ Similarly, the Kraemer equation describes the concentration dependence of the inherent viscosity $\left(\eta_{i n h}\right)$ of protein solutions: ${ }^{48,49}$

$$
\eta_{\text {inh }}=\frac{\ln \left(\eta_{r}\right)}{c}=[\eta]+\left(k_{H}-\frac{1}{2}\right)[\eta]^{2} c
$$

The intrinsic viscosity $[\eta]$ was determined by intercepting the Huggins plot based on eqn (4) and the Kraemer plot based on eqn (5) at the zero concentration $(c=0)$ as shown in Fig. 1. The intrinsic viscosity $[\eta]$ values for collagen, fibrinogen and thrombin are $10.55 \mathrm{dL} / \mathrm{g}, 0.2056 \mathrm{dL} / \mathrm{g}$, and 0.022 $\mathrm{dL} / \mathrm{g}$, respectively. The $[\eta]$ values for collagen, fibrinogen, and thrombin from other studies are $10.75 \mathrm{dL} / \mathrm{g}, 0.27 \mathrm{dL} / \mathrm{g}$, and $0.038 \mathrm{dL} / \mathrm{g}$, respectively. ${ }^{50}$ The lower $[\eta]$ values of fibrinogen and thrombin in this study are because of the lower purity/quality of these two proteins. For example, 
$\geq 75 \%$ of fibrinogen used in this study was clottable according to the manufacturer. In contrast, $\geq$ $96 \%$ of fibrinogen used in a previously published study by Shulman et al. ${ }^{51}$ was clottable according to those authors.
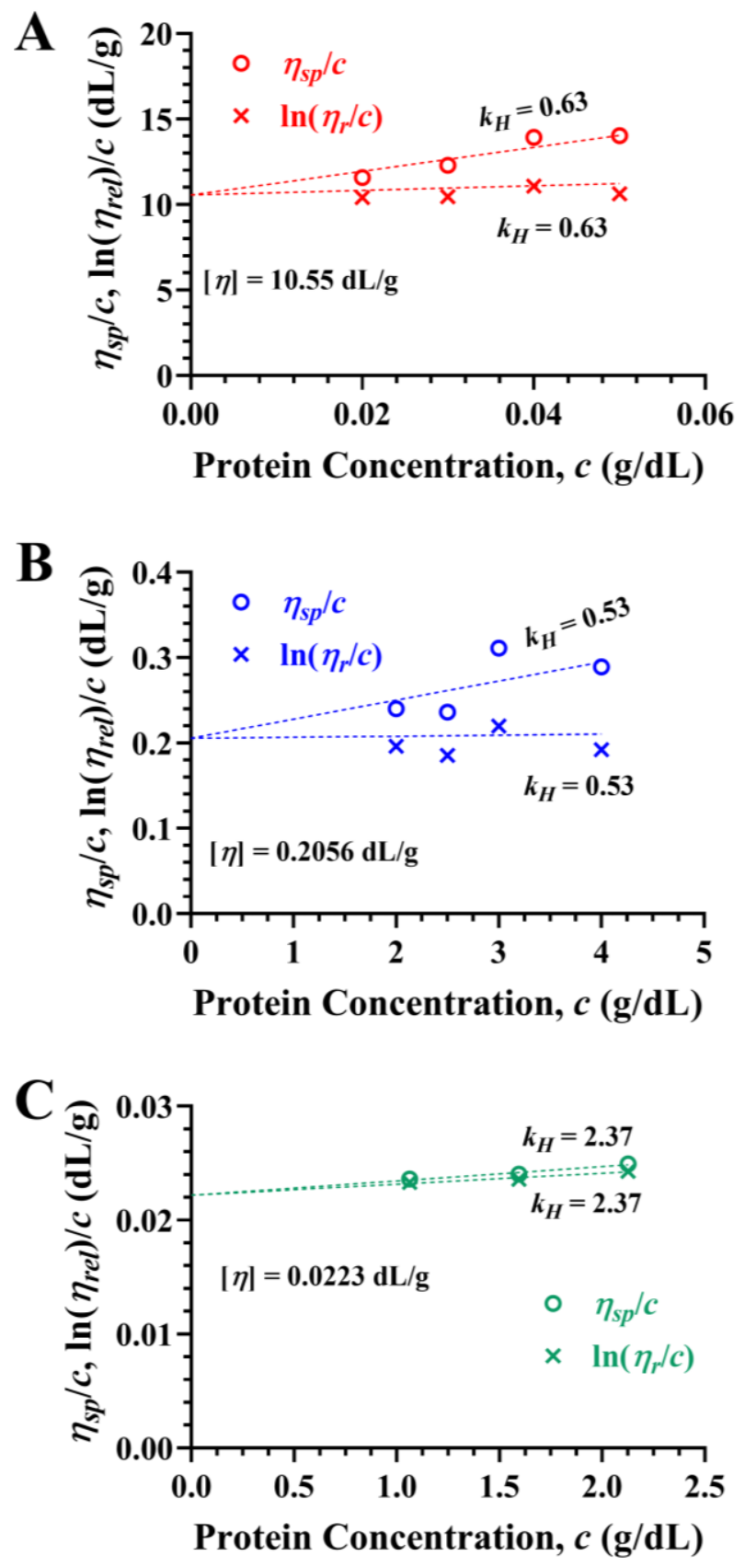
Fig. 1 Huggins-Kraemer plots for surfactant-free protein solutions obtained with the Ubbelohde viscometer. (A) Collagen solutions (red) with concentrations of 0.02,0.03, 0.04, and 0.05 g/dL at $4{ }^{\circ} \mathrm{C}$. (B) Fibrinogen solutions (blue) with concentrations of 1.5, 2.0, 2.5, 3.0, and $4.0 \mathrm{~g} / \mathrm{dL}$ at 25 ${ }^{\circ} \mathrm{C}$. (C) Thrombin solutions (green) with concentrations of $1.06,1.60$, and $2.13 \mathrm{~g} / \mathrm{dL}$ at $25^{\circ} \mathrm{C}$. Note that $2.13 \times 10^{-3} \mathrm{~g} / \mathrm{dL}$ of thrombin correspond to $1 \mathrm{U} / \mathrm{ml}$. Mean data are plotted ( $n=3$ replicates).

The overlap concentration $c^{*}$, the concentration at which protein/polymer chains begin to overlap in the solutions, was evaluated using the following relationship: ${ }^{52}$

$$
c^{*}=\frac{0.77}{[\eta]}
$$

Accordingly, $c^{*}$ values for collagen, fibrinogen, and thrombin are $0.73 \mathrm{mg} / \mathrm{mL}, 37 \mathrm{mg} / \mathrm{mL}$, and $345 \mathrm{mg} / \mathrm{mL}(\approx 16200 \mathrm{U} / \mathrm{mL})$, respectively. However, the overlap concentration $c^{*}$ was traditionally evaluated by plotting the specific viscosity $\eta_{s p}$ against the function $[\eta] c$ as presented in Fig. 2. The slope of the specific viscosity $\eta_{s p}$ curve of collagen changes from 1 to 2 at $[\eta] c$ between $0.63(c=0.6 \mathrm{mg} / \mathrm{mL})$ and $0.79(c=0.75 \mathrm{mg} / \mathrm{mL})$ on the $\log -\log$ plot of that figure and the overlap concentration $c^{*}$ for collagen is $\sim 0.73 \mathrm{mg} / \mathrm{mL}$, in agreement with eqn (6). However, this value is not in agreement with the $c^{*}$ value of $3-5 \mathrm{mg} / \mathrm{mL}$, which was reported by Gobeaux et al. ${ }^{25}$ Those authors measured the viscosity of collagen solutions at a $\mathrm{pH}$ of 2.5 with a cone-andplate rheometer at a higher temperature of $20^{\circ} \mathrm{C}$ resulting in the different $c^{*}$ values. The slope of the $\eta_{s p}$ curve of fibrinogen in Fig. 2 changes from 1 to 2 at $[\eta] c$ between $0.62(c=30 \mathrm{mg} / \mathrm{mL})$ and $0.82(c=40 \mathrm{mg} / \mathrm{mL})$ and the overlap concentration $c^{*}$ for fibrinogen is $\sim 37 \mathrm{mg} / \mathrm{mL}$, which is in agreement with eqn (6) as well. Unfortunately, $c^{*}$ for fibrinogen is not available in the literature. Collagen exhibits the highest intrinsic viscosity $[\eta]$ and hence the highest viscosity of the three types of protein solutions for a given protein concentration $c$. Analogously, the thrombin exhibits the lowest viscosity for a given protein concentration. 


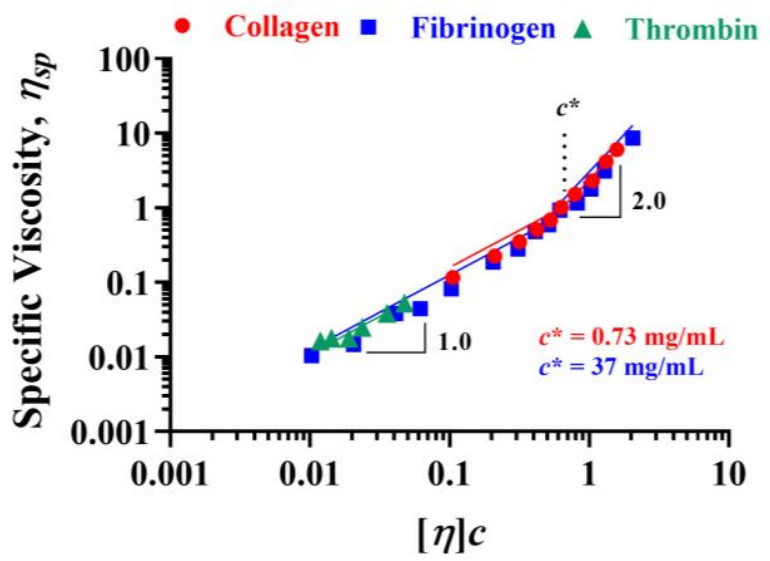

Fig. 2 Specific viscosity of surfactant-free protein solutions as a function of $[\eta] c$ determined with the Ubbelohde viscometer. The collagen solutions (red circles) were maintained at $4{ }^{\circ} \mathrm{C}$ whereas the fibrinogen (blue squares) and thrombin (green triangles) solutions were maintained at $25{ }^{\circ} \mathrm{C}$ during the experiments. Note that $2.13 \times 10^{-3} \mathrm{~g} / \mathrm{dL}$ of thrombin correspond to $1 \mathrm{U} / \mathrm{ml}$. Mean data are plotted ( $n=3$ replicates).

\subsection{Rheology of surfactant-free protein solutions}

The apparent bulk viscosity as a function of shear rate, namely flow curve, is presented in Fig. 3 for the protein solutions investigated in this work. The protein solutions show a non-Newtonian response and their viscosity decreases with shear rate, with the exception of thrombin solutions from 0.01 to $1 \mathrm{U} / \mathrm{mL}$, which show a Newtonian response. Those thrombin solutions are very dilute and their viscosity does not change with both concentration and shear rate. Perhaps there is a certain critical concentration for thrombin solutions, between $1-5 \mathrm{U} / \mathrm{mL}$, above which they show the non-Newtonian response. The apparent non-Newtonian response of protein solutions can arise because of the formation of viscoelastic protein film at the air/water interface which contributes an apparent yield stress $\left(\sigma_{y}\right)$. The magnitude of the yield is controlled by the geometry of rheometry fixtures. ${ }^{13,14}$ Further, for a given geometry, the individual properties of the protein monomers may also control the yield stress. Accordingly, the low shear rate viscosity and high shear rate viscosity 
appears to change differently with protein concentration for collagen, fibrinogen, and thrombin solutions. For example, the low shear rate viscosity and high shear rate viscosity of collagen solutions increase with concentration. Contrastingly, the low shear viscosity of fibrinogen solutions is relatively constant does not increase with concentration whereas their high shear rate viscosity increases with concentration. The low shear rate viscosity increases with concentration for thrombin solutions between 5 and $100 \mathrm{U} / \mathrm{mL}$. However, the high shear rate viscosity does not increase significantly with concentration for thrombin solutions between 5 and $200 \mathrm{U} / \mathrm{ml}$. 

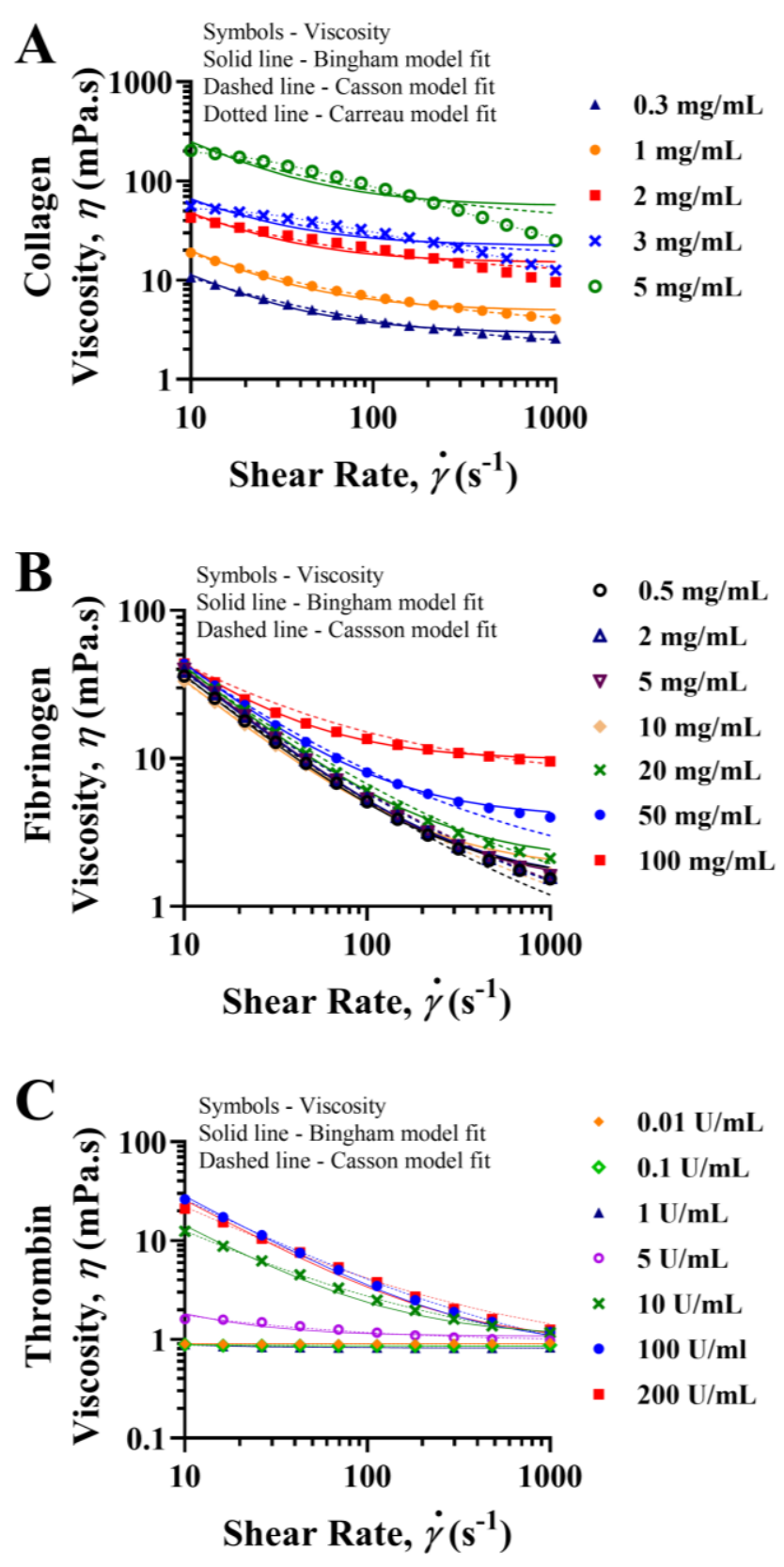

Fig. 3 Apparent bulk viscosity of surfactant-free protein solutions as a function of shear rate measured with the cone-and-plate rheometer. (A) Collagen solutions with concentrations of 0.3, 1.0, 2, 3, and $5 \mathrm{mg} / \mathrm{mL}$ at $4{ }^{\circ} \mathrm{C}$. (B) Fibrinogen solutions with concentrations of $0.5,2,5,10,20$, 50 , and $100 \mathrm{mg} / \mathrm{mL}$ at $25^{\circ} \mathrm{C}$. (C) Thrombin solutions with concentrations of $0.01,0.10,1,5,10$, 100 , and $200 \mathrm{U} / \mathrm{mL}$ at $25^{\circ} \mathrm{C}$. Note that $1 \mathrm{U} / \mathrm{ml}$ of thrombin corresponds to $2.13 \times 10^{-2} \mathrm{mg} / \mathrm{mL}$. Mean data and standard deviation are plotted ( $n=3$ replicates) with the exception of 3 and 5 $\mathrm{mg} / \mathrm{mL}$ collagen solutions ( $n=2$ replicates $)$. 
The viscosity data in Fig. 3 show a Bingham model ${ }^{53}$ (eqn (7)) response in the dilute and semidilute unentangled regimes. The Bingham model, in general, describes the dependence of the apparent bulk viscosity $(\eta(\dot{\gamma}))$ at a specific shear rate $(\dot{\gamma})$ on the apparent yield stress $\sigma_{y}$, the minimum shear stress at which solutions showing a solid-like response begin to flow: ${ }^{13,14}$

$$
\eta(\dot{\gamma})=\eta_{\infty}+\frac{\sigma_{y}}{\dot{\gamma}}
$$

where $\eta_{\infty}$ is the Newtonian viscosity at high shear rates (see ESI $\dagger$ Table SI 1 for model fit parameters). The Bingham model fails for semidilute unentangled collagen solutions at the high shear rates because of their more pronounced shear-thinning behavior. The shear-thinning behavior generally arises because of the alignment of protein chains in the direction of flow with increasing shear rate. ${ }^{54}$ The shear-thinning behavior of collagen solutions, which exhibit the highest intrinsic viscosity, is more pronounced among the three protein solution types at high protein concentrations and high shear rates. Because of failure of the Bingham model, the Casson model was also used to study the behavior of collagen solutions: ${ }^{55}$

$$
\eta(\dot{\gamma})=\left[\left(\eta_{\infty}\right)^{1 / 2}+\left(\frac{\sigma_{\mathrm{y}}}{\dot{\gamma}}\right)^{1 / 2}\right]^{2}
$$

Although the Casson model fit is better than the Bingham model fit (see ESI Tables SI 1 - 2), it also fails at the high shear rates. The Bingham and Casson models also fail at the low shear rates for 3 and $5 \mathrm{mg} / \mathrm{mL}$ collagen solutions because the bulk contribution to their apparent viscosity (or measured torque) significantly dominates the interfacial contribution. Accordingly, the flow behavior of these two solutions follows a shear-thinning behavior which is best described by the Carreau model. This model captures the shear rate dependence of the apparent bulk viscosity: ${ }^{56,57}$

$$
\frac{\eta(\dot{\gamma})}{\eta_{0}}=\left[1+(\lambda \dot{\gamma})^{\alpha}\right]^{m-1 / \alpha}
$$

where $\eta_{0}$ is the zero-shear viscosity, $\alpha$ is a constant parameter (a value of 2 was chosen), $\lambda$ is the characteristic time of the material corresponding to the inverse of shear rate at the onset of the thinning, and $m$ is the shear-thinning exponent (see ESI† Table SI 3 for model fit parameters). 
The apparent yield stress $\sigma_{y}$ for collagen solutions, which is determined with both the Bingham and Casson models, increases with concentration between 0.2 and $5 \mathrm{mg} / \mathrm{mL}$ as shown in Fig. 4. This is because the triple helix monomers of collagen may not readily denature at the air/water interface to form a strong viscoelastic solid layer because of the presence of glycine at the center of the helix, which allows tight packing of the three chains which constitute the helix. ${ }^{58}$ The yield stress for fibrinogen solutions does not increase with concentration. This is because fibrinogen monomers, which are analogous to flexible polymer chains, adsorb as much as they are going to even in dilute solutions at the air/water interface and may denature, forming a strong viscoelastic solid layer at the interface. The yield stress for thrombin solutions increases with concentration because globular monomers of thrombin, unlike flexible polymer chains, may not readily denature at the air/water interface to form a strong viscoelastic solid layer.

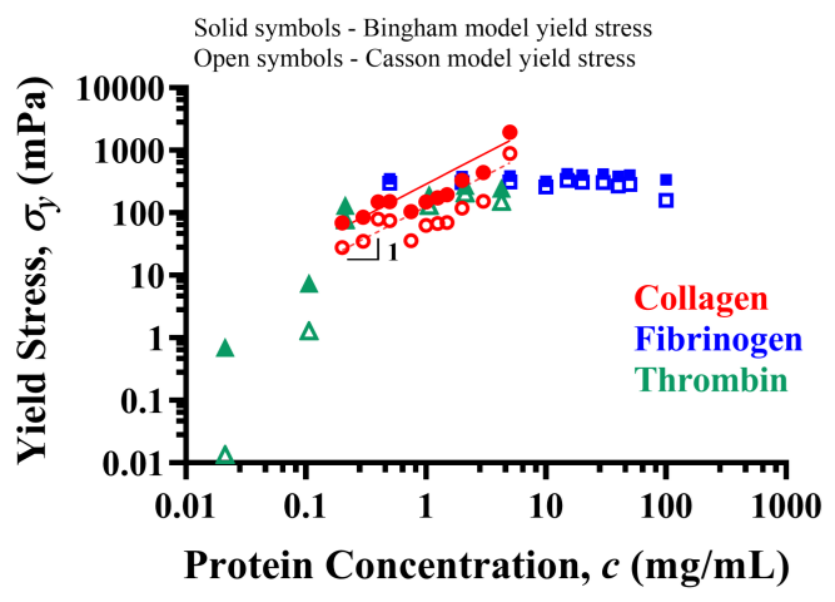

Fig. 4 Apparent yield stress of surfactant-free protein solutions as a function of their concentration evaluated by fitting the Bingham (solid symbols) and Casson (open symbols) models to the apparent bulk viscosities of those solutions measured with cone-and-plate rheometer. Collagen (red circles), fibrinogen (blue squares), and thrombin (green triangles). Note that $2.13 \times 10^{-2}$ $\mathrm{mg} / \mathrm{mL}$ of thrombin corresponds to $1 \mathrm{U} / \mathrm{mL}$. 
The apparent bulk moduli $G^{\prime}$ and $G^{\prime \prime}$ of protein solutions obtained with the dynamic amplitude sweeps, corresponding to an oscillation frequency of $1 \mathrm{rad} / \mathrm{s}$, as a function of protein concentration are presented in Fig 5. The average values of the moduli from three different measurements within the linear viscoelastic region of the DSS plots (see ESI $\uparrow$ Fig. SI. 1 for more details) are presented in the figure. The moduli increase with concentration for the dilute and semidilute unentangled protein solutions $(c \geq 0.1 \mathrm{mg} / \mathrm{mL})$ and those solutions show a viscoelastic solid-like response. Interestingly, the viscoelastic response of semidilute unentangled collagen solutions is identical to the viscoelastic response of dilute fibrinogen and thrombin solutions of comparable concentrations. However, the viscoelastic protein film at the air/water interface can misrepresent the true viscoelastic behavior of the protein solutions through its interfacial contribution.

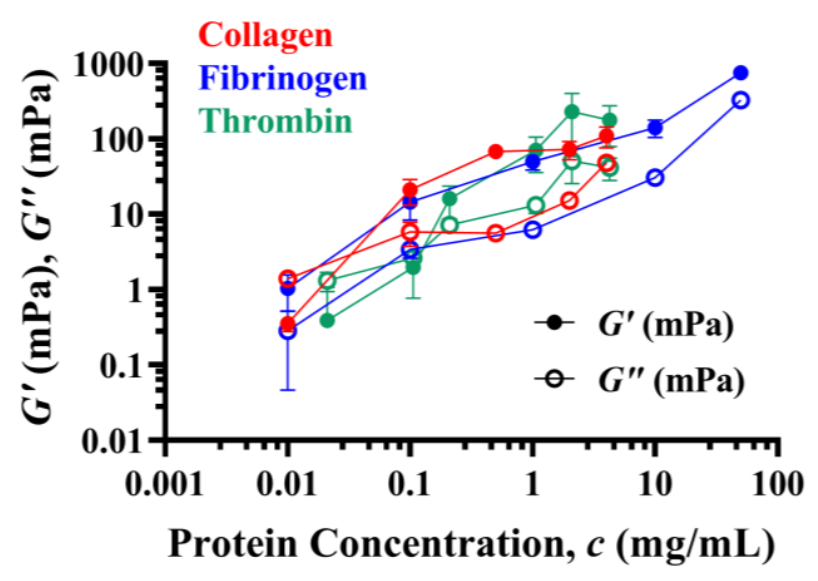

Fig. 5 Oscillatory rheology measurements of surfactant-free protein solutions as a function of their concentrations measured with the cone-and-plate rheometer. The bulk storage modulus $G^{\prime}$ (solid symbols) and the bulk loss modulus $G^{\prime \prime}$ (open symbols) refer to an oscillation frequency of $1 \mathrm{rad} / \mathrm{s}$ within the linear viscoelastic region. The measurements of collagen solutions (red) with concentrations of $0.01,0.10,0.50,2$, and $4 \mathrm{mg} / \mathrm{mL}$ were performed at $4{ }^{\circ} \mathrm{C}$. The measurements of fibrinogen (blue) solutions with concentrations of $0.01,0.10,1,10$, and $50 \mathrm{mg} / \mathrm{mL}$ were performed at $25{ }^{\circ} \mathrm{C}$. The measurements of thrombin (green) solutions with concentrations of $0.021,0.106$, 
$0.212,1.06,2.12$, and $4.25 \mathrm{mg} / \mathrm{mL}$ were performed at $25{ }^{\circ} \mathrm{C}$. Note that $2.13 \times 10^{-2} \mathrm{mg} / \mathrm{mL}$ of thrombin corresponds to $1 \mathrm{U} / \mathrm{mL}$. Mean data and standard deviation are plotted ( $n=3$ replicates).

The interfacial rheology measurements obtained with a double-wall ring geometry are presented in Fig. 6 in terms of interfacial storage modulus $G^{\prime}$ and loss modulus $G^{\prime \prime}$, corresponding to an oscillation frequency of $1 \mathrm{rad} / \mathrm{s}$. The average values of the moduli from three different measurements within the linear viscoelastic region of the DSS or dynamic frequency sweep plots (see ESI $\uparrow$ Figs. SI. 2-4 for more details) are presented in the figure. The interfacial rheology measurements confirm the formation of a viscoelastic film at the air/water interface for collagen, fibrinogen, and thrombin solutions with concentration $c \geq 0.1 \mathrm{mg} / \mathrm{mL}$. The interfacial storage modulus $G^{\prime}$ is larger than loss modulus $G^{\prime \prime}$, suggesting a viscoelastic solid-like response at the interface. The viscoelastic solid-like response of the surfactant-free collagen and thrombin solutions increase with concentration. The viscoelastic solid-like response of fibrinogen solutions does not increase with concentration. In addition, the viscoelastic adsorbed layer at the air/water interface is strongly elastic at all concentrations since $G^{\prime} \gg G^{\prime \prime}$ at all measurable angular frequencies (see ESI† Fig. SI. 4). Thus, the low shear rate viscosity (Fig. 3) and apparent yield stress $\sigma_{y}$ of fibrinogen solutions (Fig. 4) do not depend on protein concentration. The viscoelastic solid-like response is more apparent for fibrinogen and thrombin solutions because their interface was allowed to develop for $10 \mathrm{~min}$ before each measurement was taken. Whereas, the interfacial measurements of collagen were taken immediately after loading the samples because the collagen at the surface, which was exposed to the ambient air, was crosslinking in about 5 min. While the surface-induced aggregation of the globular proteins has been already reported by Sharma et al. ${ }^{13}$ and Castellanos et al., ${ }^{14}$ the viscoelastic response of fibrous proteins at the solution-air interface represents a new finding, having a significant impact in the bulk response of such protein solutions during steady and dynamic shear rheology measurements. 


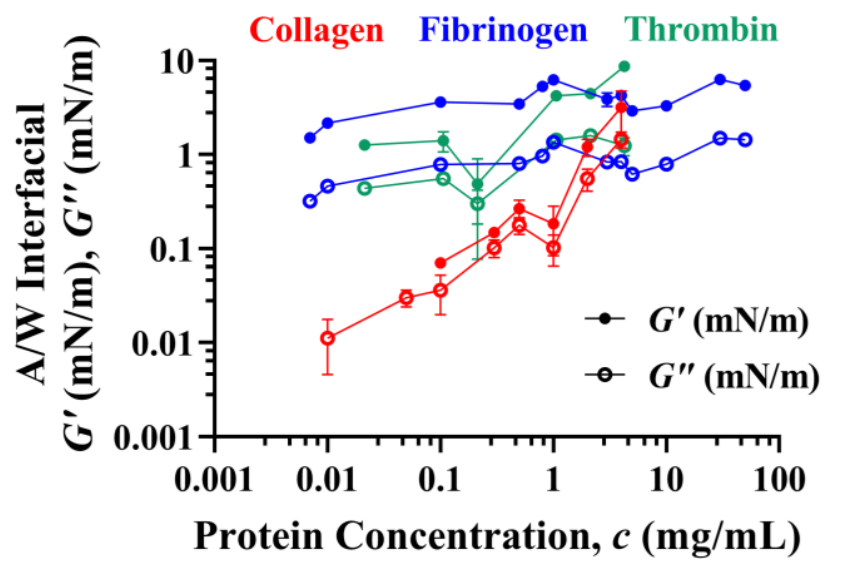

Fig. 6 Interfacial oscillatory rheology measurements of surfactant-free protein solutions as a function of their concentrations measured with the double wall ring geometry. The interfacial storage modulus $G^{\prime}$ (solid symbols) and the interfacial loss modulus $G^{\prime \prime}$ (open symbols) of the solutions were measured with an oscillation frequency of $1 \mathrm{rad} / \mathrm{s}$ within the linear viscoelastic regime. The measurements of collagen (red) solutions with concentrations of 0.01, 0.05, 0.10, 0.30, $0.50,1,2$, and $4 \mathrm{mg} / \mathrm{mL}$ were performed at $4{ }^{\circ} \mathrm{C}$. The measurements of fibrinogen (blue) solutions with concentrations of $0.007,0.010,0.10,0.50,0.80,1,3,4,5,10,30$, and $50 \mathrm{mg} / \mathrm{mL}$ were performed at $25^{\circ} \mathrm{C}$. The measurements of thrombin (green) solutions with concentrations of 0.021 , $0.106,0.212,1.06,2.12$, and $4.25 \mathrm{mg} / \mathrm{mL}$ were performed at $25^{\circ} \mathrm{C}$. Note that $2.13 \times 10^{-2} \mathrm{mg} / \mathrm{mL}$ of thrombin corresponds to $1 \mathrm{U} / \mathrm{mL}$. Mean data and standard deviation are plotted $(n=3$ replicates).

\subsection{Rheology of surfactant-laden protein solutions}

Rheology measurements were also performed for surfactant-laden protein solutions with the coneand-plate rheometer to understand the interfacial effects in the presence of a non-ionic surfactant, such as polysorbate 80 . This surfactant can prevent the surface-induced aggregation of proteins, allowing the estimation of the true bulk rheology of the protein solutions. The bulk flow curves of the protein solutions at various concentrations are presented in Fig. 7. The collagen solutions show a non-Newtonian shear-thinning behavior which follows the Carreau model (see ESI $\uparrow$ Table SI 3 for model fit parameters). Since $G^{\prime}<G^{\prime \prime}<0.03 \mathrm{mN} / \mathrm{m}$ for surfactant-laden collagen solution, we 
conclude that collagen does not adsorb at the air/water interface with the surfactant present. Interestingly, the zero-shear viscosity $\eta_{0}$ and the model fit parameters for $5 \mathrm{mg} / \mathrm{mL}$ collagen solutions with or without polysorbate 80 are identical, confirming the dominance of bulk contribution over interfacial contribution at high collagen concentrations for the surfactant-free solutions. Fibrinogen solutions with $c \geq 40 \mathrm{mg} / \mathrm{mL}$ also show a shear-thinning behavior which follows the Carreau model (see ESI $\uparrow$ Table SI 3 for model fit parameters). Conversely, dilute fibrinogen $(c<40 \mathrm{mg} / \mathrm{mL})$ and thrombin solutions $(c<200 \mathrm{U} / \mathrm{mL})$ show a Newtonian behavior. The low shear rate viscosity of fibrinogen solutions increases with concentration, which seldom exceeds the high shear viscosity, signifying the absence of the yield stress and surface-induced aggregation of proteins. 

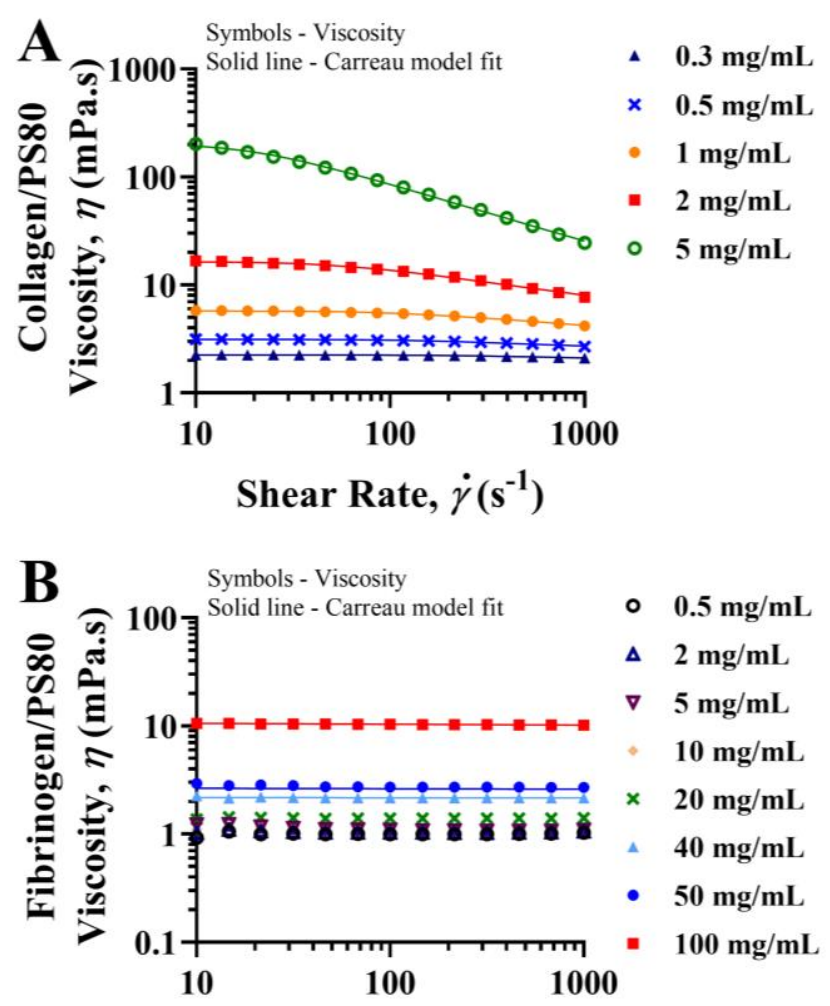

Shear Rate, $\dot{\gamma}\left(\mathrm{s}^{-1}\right)$

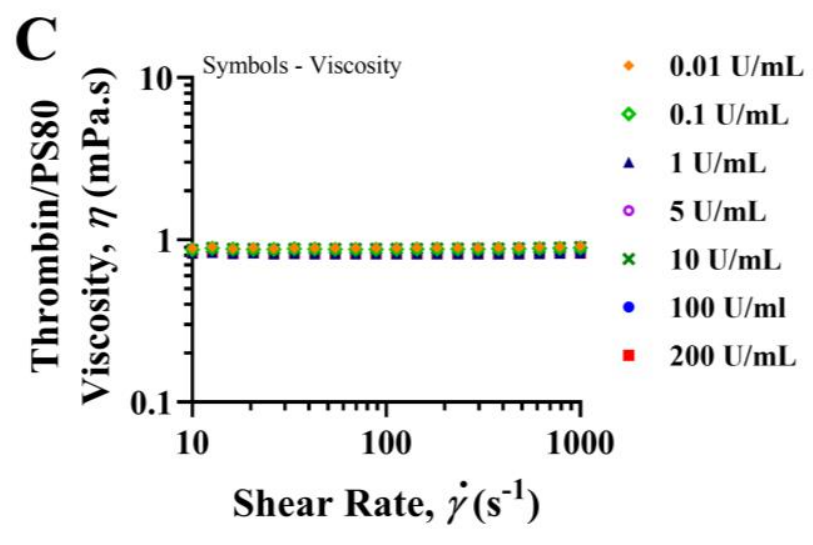

Fig. 7 Apparent bulk viscosity of surfactant-laden protein solutions as a function of shear rate measured with the cone-and-plate rheometer. (A) Collagen solutions with concentrations of 0.3, $0.5,1.0,2$, and $5 \mathrm{mg} / \mathrm{mL}$ containing $0.001 \mathrm{v} / \mathrm{v} \%$ polysorbate 80 at $4{ }^{\circ} \mathrm{C}$. (B) Fibrinogen solutions with concentrations of $0.5,2,5,10,20,40,50$, and $100 \mathrm{mg} / \mathrm{mL}$ containing $0.1 \mathrm{v} / \mathrm{v} \%$ polysorbate 80 at $25^{\circ} \mathrm{C}$. (C) Thrombin solutions with concentrations of $0.01,0.10,1,5,10,100$, and $200 \mathrm{U} / \mathrm{mL}$ containing $0.001 \mathrm{v} / \mathrm{v} \%$ polysorbate 80 at $25{ }^{\circ} \mathrm{C}$. Note that $1 \mathrm{U} / \mathrm{ml}$ of thrombin corresponds to 2.13 
$\times 10^{-2} \mathrm{mg} / \mathrm{mL}$. Mean data and standard deviation are plotted ( $n=3$ replicates) with the exception of $5 \mathrm{mg} / \mathrm{mL}$ collagen solutions ( $n=2$ replicates).

For fibrinogen solutions, the volume of polysorbate 80 required to prevent the apparent yield stress $\sigma_{y}$ increases with concentration as shown in Fig. 8. The minimum concentration of polysorbate 80 required to prevent the yield stress for 5 and $10 \mathrm{mg} / \mathrm{mL}$ solutions is $0.001 \mathrm{v} / \mathrm{v} \%$. Whereas, even at a concertation of $0.01 \mathrm{v} / \mathrm{v} \%$ of polysorbate 80 , the yield stress is present for 20 mg/mL fibrinogen solutions. According to Figs. 4 and 6, the yield stress and the interfacial elastic moduli do not increase significantly with concentration for surfactant-free fibrinogen solutions, signifying the involvement of similar amount of proteins at the interface across all protein concentrations. However, the concentration of polysorbate 80 required to prevent the yield stress does not remain constant and increases by more than 10-fold when the concentration of fibrinogen solutions increases from 10 to $20 \mathrm{mg} / \mathrm{mL}$. Such an increase in the concentration of polysorbate 80 is perhaps because some of polysorbate 80 molecules are interacting with and binding to some of the fibrinogen monomers in the bulk. As a result, $0.1 \mathrm{v} / \mathrm{v} \%$ of polysorbate 80 was added to fibrinogen solutions whereas $0.001 \mathrm{v} / \mathrm{v} \%$ of the surfactant was added to collagen and thrombin solutions to obtain the same effect.

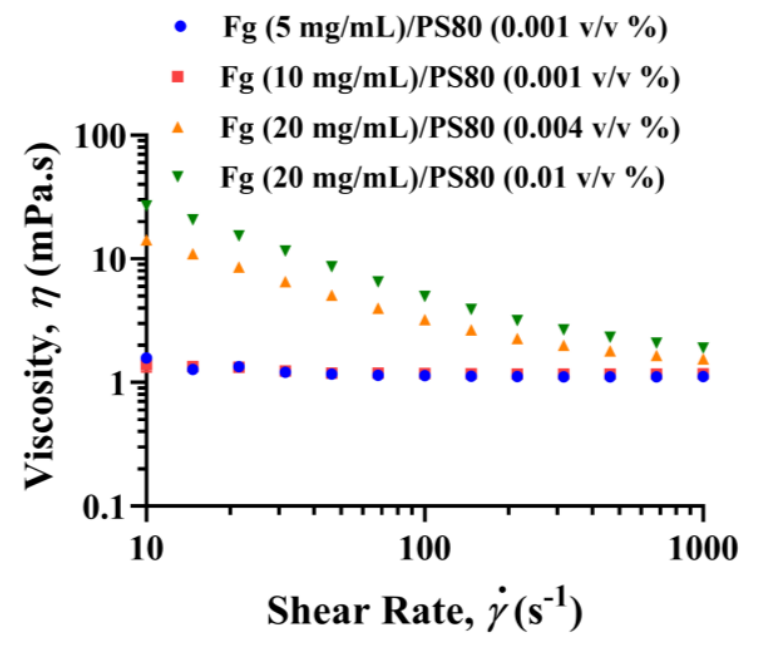


Fig. 8 Apparent bulk viscosity of surfactant-laden (PS80) fibrinogen (Fg) solutions at $25{ }^{\circ} \mathrm{C}$ as a function of shear rate measured using the cone-and-plate rheometer.

The apparent bulk storage modulus $G^{\prime}$ and loss modulus $G^{\prime \prime}$ of the protein solutions obtained with dynamic amplitude sweeps at an oscillation frequency of $1 \mathrm{rad} / \mathrm{s}$ are presented in Fig 9. The average values of the moduli from three different measurements within the linear viscoelastic region are presented in the figure. The dilute and semidilute unentangled protein solutions $(c \geq 0.1 \mathrm{mg} / \mathrm{mL})$ show a viscoelastic liquid-like response unlike the surfactant-free protein solutions, which show a viscoelastic solid-like response. Hence, the addition of polysorbate 80 suppresses the surface-induced aggregation of proteins and prevents the interfacial contribution to the bulk rheology of the protein solutions. The viscoelastic response of collagen solutions increases with concentration whereas it is relatively constant for fibrinogen and thrombin solutions with concentration $c \leq 10 \mathrm{mg} / \mathrm{mL}$. The viscoelastic response of fibrinogen solutions increases with concentration between 10 and $50 \mathrm{mg} / \mathrm{mL}$. Furthermore, the viscoelastic response of semidilute unentangled collagen solutions is greater than the viscoelastic response of dilute fibrinogen and thrombin solutions of comparable concentrations.

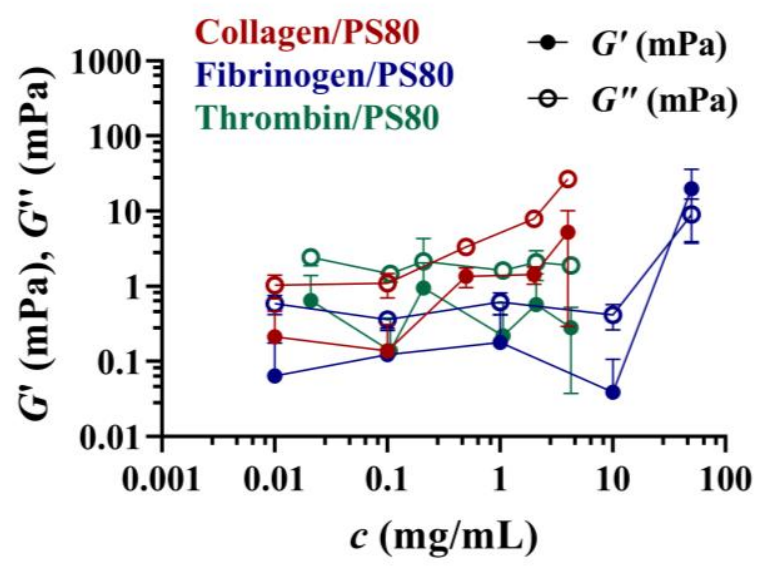


Fig. 9 Oscillatory rheology measurements of surfactant-laden protein solutions as a function of concentration measured with the cone-and-plate rheometer. The bulk storage modulus $G^{\prime}$ (solid symbols) and the bulk loss modulus $G^{\prime \prime}$ (open symbols) were measured with an oscillation frequency of $1 \mathrm{rad} / \mathrm{s}$ within the linear viscoelastic region. The measurements of collagen (red) solutions with concentrations of $0.01,0.10,0.50,2$, and $4 \mathrm{mg} / \mathrm{mL}$ containing $0.001 \mathrm{v} / \mathrm{v} \%$ polysorbate 80 were performed at $4{ }^{\circ} \mathrm{C}$. The measurements of fibrinogen (blue) solutions with concentrations of $0.01,0.10,1,10$, and $50 \mathrm{mg} / \mathrm{mL}$ containing $0.1 \mathrm{v} / \mathrm{v} \%$ polysorbate 80 were performed at $25^{\circ} \mathrm{C}$. The measurements of thrombin (green) solutions with concentrations of 0.021 , $0.106,0.212,1.06,2.12$, and $4.25 \mathrm{mg} / \mathrm{mL}$ containing $0.001 \mathrm{v} / \mathrm{v} \%$ polysorbate 80 were performed at $25^{\circ} \mathrm{C}$. Note that $2.13 \times 10^{-2} \mathrm{mg} / \mathrm{mL}$ of thrombin corresponds to $1 \mathrm{U} / \mathrm{mL}$. Mean data and standard deviation are plotted ( $n=3$ replicates).

\subsection{Intrinsic viscosity of proteins in surfactant-laden solutions}

Intrinsic viscosity $[\eta]$ and overlap concentration $c^{*}$ of collagen and fibrinogen in surfactant-laden solutions were determined with the apparent bulk viscosity measurements presented in Fig. 7. Thrombin solutions are excluded from this analysis because the investigated solutions were very dilute and increasing their concentration is cost prohibitive and not biologically relevant for 3D bioprinting applications. The zero-shear viscosity values of collagen solutions, which were evaluated with eqn (9), were used for determining the specific viscosity $\eta_{s p}$, reduced viscosity $\eta_{r e d}$, and inherent viscosity $\eta_{i n h}$ of those solutions. Similarly, the zero-shear viscosity values of fibrinogen solutions with $c \geq 40 \mathrm{mg} / \mathrm{mL}$, which were evaluated with eqn (9) and the Newtonian viscosity values of fibrinogen solutions with $c<40 \mathrm{mg} / \mathrm{mL}$ at the shear rates between 10 and $1000 \mathrm{~s}^{-1}$ were used for determining the $\eta_{s p}, \eta_{r e d}$, and $\eta_{\text {inh }}$ of the solutions. The intrinsic viscosity of proteins was determined using the Huggins-Kraemer plots, which are presented in Fig. 10. The intrinsic viscosity of collagen is $15.35 \mathrm{dL} / \mathrm{g}$ and that of fibrinogen is $0.1949 \mathrm{dL} / \mathrm{g}$. 

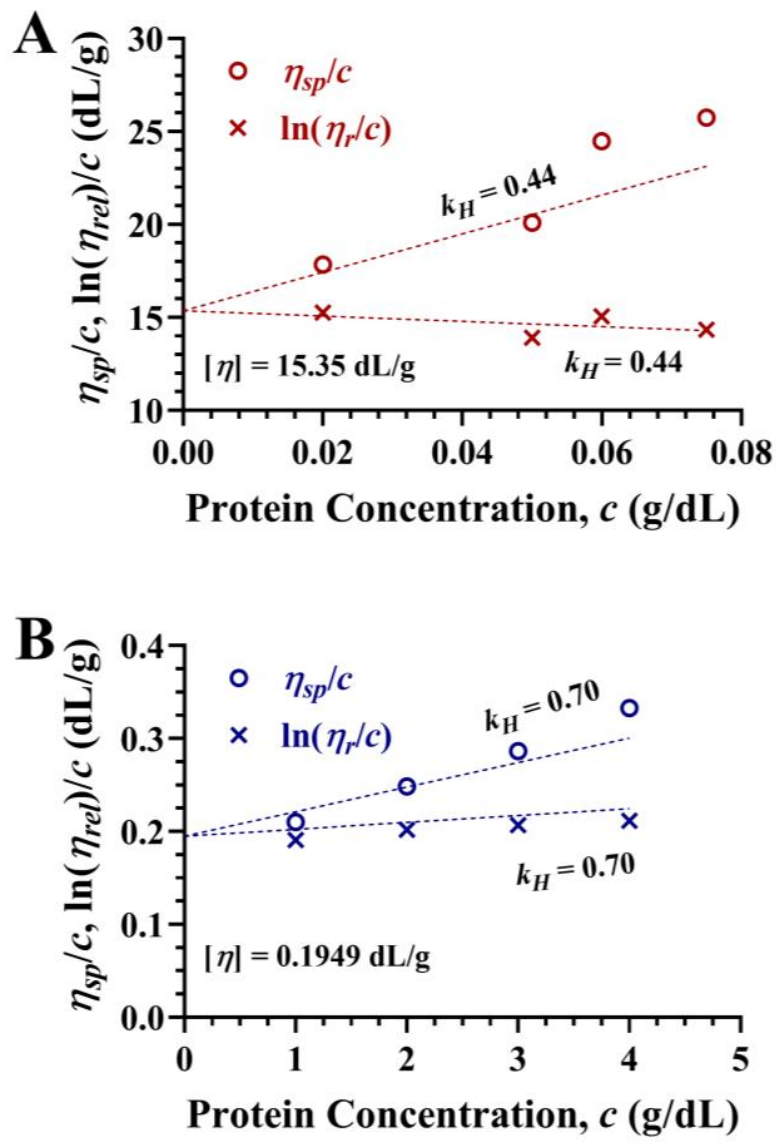

Fig. 10 Huggins-Kraemer plots of surfactant-laden protein solutions obtained with the cone-andplate rheometer. (A) Collagen (red) solutions with concentrations of 0.5, 0.6, 0.75, 1.0, 1.25, 1.50, and $2.50 \mathrm{mg} / \mathrm{mL}$ containing $0.001 \mathrm{v} / \mathrm{v} \%$ polysorbate 80 at $4{ }^{\circ} \mathrm{C}$. (B) The fibrinogen (blue) solutions with concentrations of $10,15,20,30$, and $40 \mathrm{mg} / \mathrm{mL}$ containing $0.1 \mathrm{v} / \mathrm{v} \%$ polysorbate 80 at $25^{\circ} \mathrm{C}$. Mean data are plotted ( $n=3$ replicates).

The Mark-Houwink equation relates the intrinsic viscosity $[\eta]$ of a protein/polymer to its molecular weight $(M):^{12}$

$$
[\eta]=K M^{a}
$$


where $K$ and $a$ (commonly referred to as the Mark-Houwink exponent) are constant parameters. The exponent $a$ depends on the solvent quality and structure of the dissolved polymer. ${ }^{59}$ The molecular weight of collagen type I, extracted from the rat tail tendon, which was measured with sodium dodecyl sulfate polyacrylamide gel electrophoresis (SDS-PAGE) from our previously published study is approximately $375 \mathrm{kDa} .{ }^{34}$ The molecular weight of collagen in surfactant-free protein solutions, which was evaluated with $[\eta]=10.55 \mathrm{dL} / \mathrm{g}$ from the Ubbelohde viscometer measurements and eqn (10), is $330 \mathrm{kDa}$. Whereas, the molecular weight of collagen in the surfactant-laden protein solutions, which was evaluated with $[\eta]=15.35 \mathrm{dL} / \mathrm{g}$ from the cone-andplate measurements and eqn (10), is $406 \mathrm{kDa}$. The values of $K=1.23 \times 10^{-9}[(\mathrm{dL} / \mathrm{g})(\mathrm{mol} / \mathrm{g})]$ and $a=1.8$ were obtained from a previously published study by Doty et al. ${ }^{60}$ Unfortunately, the parameter $K$ for fibrinogen in aqueous buffer solutions is not available in the literature. However, fibrinogen has a comparable intrinsic viscosity in both surfactant-laden and surfactant-free solutions as listed in Table 1.

Table 1 Intrinsic viscosity of proteins evaluated using the Huggins-Kraemer plots (Eqs. 4 and 6).

\begin{tabular}{cccccc}
\hline Solution & Device & PS80 $(\mathbf{v} / \mathbf{v} \%)$ & {$[\boldsymbol{\eta}](\mathbf{d L} / \mathbf{g})$} & $\boldsymbol{k}_{\boldsymbol{H}}$ & $\boldsymbol{c}^{*}(\mathbf{m g} / \mathbf{m L})$ \\
Collagen & Ubbelohde & 0 & 10.55 & 0.63 & 0.73 \\
Collagen & Cone-and-plate & 0.001 & 15.35 & 0.44 & 0.50 \\
Fibrinogen & Ubbelohde & 0 & 0.2056 & 0.53 & 37 \\
Fibrinogen & Cone-and-plate & 0.1 & 0.1949 & 0.70 & 40 \\
Thrombin & Ubbelohde & 0 & 0.0223 & 2.37 & 345 \\
\hline
\end{tabular}

The specific viscosity $\eta_{s p}$ of surfactant-free and surfactant-laden protein solutions as a function of concentration is presented in Fig. 11. The addition of polysorbate 80 to the protein solutions did not change $\eta_{s p}$ of those solutions significantly and the values obtained with the Ubbelohde viscometer and cone-and-plate rheometer are comparable. Further, the specific 
viscosity $\eta_{s p}$ of surfactant-laden protein solutions as function of $[\eta] c$ is presented in Fig. 12. Similar to surfactant-free semidilute entangled protein solutions, the $\eta_{s p}$ of surfactant-laden semidilute unentangled protein solutions increases as the square of $[\eta] c$ and the corresponding dimensionless scaling exponent $v$ is 0.5 . Hence, the surfactant-laden collagen and fibrinogen are also $\theta$-solutions and the addition of the surfactant does not significantly alter the quality of those solutions. ${ }^{12}$ Furthermore, the overlap concentration $c^{*}$ values for collagen and fibrinogen solutions, according to eqn (6) are $0.50 \mathrm{mg} / \mathrm{mL}$ and $40 \mathrm{mg} / \mathrm{mL}$, respectively. At the same time, the slope of the specific viscosity $\eta_{s p}$ curve of collagen changes from 1 to 2 at $[\eta] c \approx 0.77(\mathrm{c}=0.5 \mathrm{mg} / \mathrm{mL})$ on the $\log -\log$ plot of Fig. 12 which is in agreement with eqn (6). Similarly, the slope of the $\eta_{s p}$ curve of fibrinogen changes from 1 to 2 at $[\eta] c \approx 0.78(c=40 \mathrm{mg} / \mathrm{mL})$ on the $\log$-log plot of the figure which is also in agreement with eqn (6).

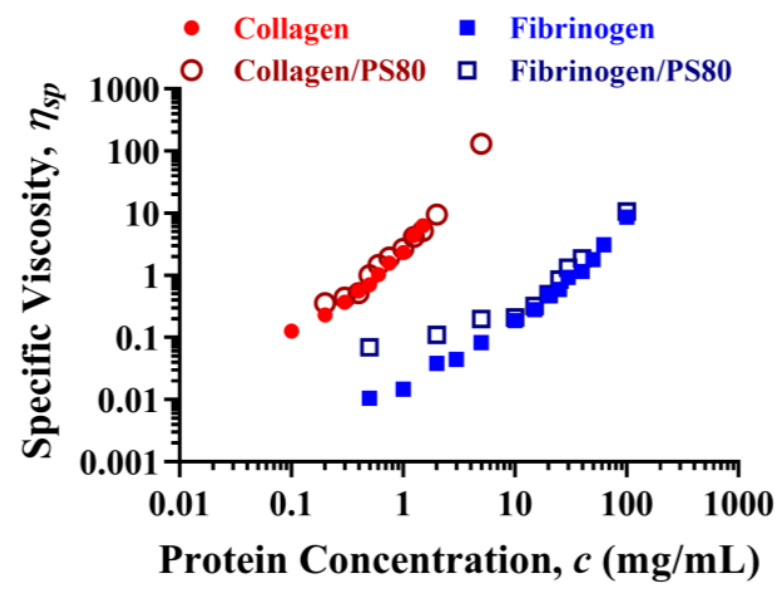

Fig. 11 Specific viscosity of surfactant-free and surfactant-laden protein solutions as a function of protein concentration determined with the Ubbelohde capillary viscometer and cone-and-plate rheometer, respectively. Surfactant-free collagen solutions (red circles) and surfactant-laden collagen solutions (red open circles) at $4{ }^{\circ} \mathrm{C}$. Surfactant-free fibrinogen solutions (blue squares) and surfactant-laden fibrinogen solutions (blue open squares) at $25^{\circ} \mathrm{C}$. Mean data are plotted $(\mathrm{n}=$ 
3 replicates) with the exception of $5 \mathrm{mg} / \mathrm{mL}$ collagen solution containing $0.001 \mathrm{v} / \mathrm{v} \%$ polysorbate 80 ( $n=2$ replicates $)$.

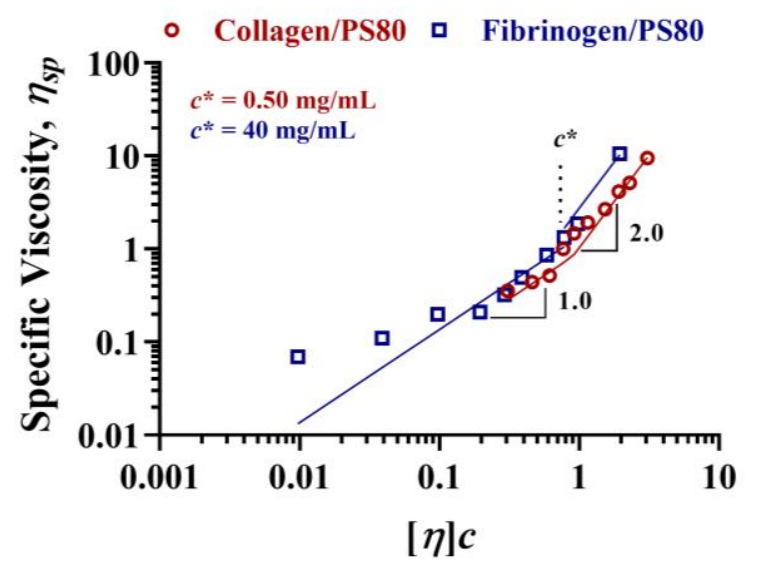

Fig. 12 Specific viscosity of surfactant-laden protein solutions as a function of $[\eta] c$ determined with the cone-and-plate rheometer. Collagen solutions (red circles) containing $0.001 \mathrm{v} / \mathrm{v} \%$ polysorbate 80 at $4{ }^{\circ} \mathrm{C}$ and fibrinogen solutions (blue squares) containing $0.1 \mathrm{v} / \mathrm{v} \%$ polysorbate 80 at $25^{\circ} \mathrm{C}$. Mean data are plotted $(\mathrm{n}=3$ replicates $)$.

The intrinsic viscosity $[\eta]$ of surfactant-laden collagen solutions is higher than the intrinsic viscosity of surfactant-free collagen solutions whereas the overlap concentration $c^{*}$ of the surfactant-laden solutions is lower than that of the surfactant-free solutions. The intrinsic viscosity $[\eta]$ of surfactant-free collagen solutions determined with the Ubbelohde viscometer is $10.55 \mathrm{dL} / \mathrm{g}$ and compares well with the values from the previous studies. ${ }^{50}$ However, that result and those results from the previous studies are not based on the zero-shear viscosity of collagen solutions and do not account for the presence of shear during measurements. An efflux time between 200 and $800 \mathrm{~s}$, for example, corresponds to a shear rate between 514 and $127 \mathrm{~s}^{-1}$ during measurements with the Ubbelohde viscometer. ${ }^{61}$ Similarly, the measurements of previous studies were performed at shear rates as high as $1820 \mathrm{~s}^{-1} .^{62}$ In addition, the Huggins coefficient $k_{H}$ of surfactant-laden collagen solutions is 0.44 , which is comparable to the theoretical value of 0.4 for rod-like particles at very low shear rates. ${ }^{63}$ Hence, the $[\eta]$ and $c^{*}$ values of surfactant-laden collagen solutions which 
are based on the zero-shear viscosity of those solutions (obtained with cone-and-plate rheometer) account for the presence shear and are more representative of true values of surfactant-free collagen solutions. This is confirmed by the molecular weight results evaluated with eqn (10) and SDS-PAGE.

Overall, the apparent bulk viscosity of protein solutions containing a very small amount of polysorbate 80 (between 0.001 and $0.1 \mathrm{v} / \mathrm{v} \%$ ), measured with the cone-and-plate rheometer, can determine specific viscosity $\eta_{s p}$, intrinsic viscosity $[\eta]$, and overlap concentration $c^{*}$ of fibrous proteins such as collagen and fibrinogen fairly quickly and accurately while consuming sample volumes as low as $700 \mu \mathrm{l}$. Although the Ubbelohde viscometer has a zero interfacial contribution, it requires a sample volume as high as $3-5 \mathrm{~mL}$ and the efflux time of collagen solutions with $c \geq$ $1.5 \mathrm{mg} / \mathrm{mL}$ exceeds the $1000 \mathrm{~s}$ limit set by the ASTM D446 - 12(2017) standard. ${ }^{64}$ As a result, the determination of true bulk viscosity of collagen solutions with $c \geq 2 \mathrm{mg} / \mathrm{ml}$ with reasonable accuracy becomes difficult with the Ubbelohde viscometer. Hence, the cone-and-plate rheometer is ideal for monitoring the batch-to-batch variations in the quality of the collagen and fibrinogen proteins and the corresponding variations in the flow behavior of those protein solutions through steady-shear viscosity measurements in the presence of very small amounts of polysorbate 80 .

\section{Drop-on-demand inkjet printing of protein solutions}

Drop-on-demand inkjet printing can accurately deliver small volumes $(1-100$ picolitres $)$ of collagen, fibrinogen, and thrombin protein solutions containing living cells and biologics (i.e, growth factors) to emulate native tissue anatomy. Although DOD inkjet printing of various buffered protein solutions containing surfactants and viscosity modifiers has been previously demonstrated by several researchers, ${ }^{65-68}$ those surfactants and viscosity modifiers may interfere with the polymerization of collagen and fibrinogen and harm living cells. ${ }^{69-71}$ Hence, DOD inkjet 
printing of surfacntant-free collagen, fibrinogen, and thrombin solutions is highly desired for 3D bioprinting applications. Drop-on-demand inkjet printing generally relies on an acoustic pressure wave resulting from localized heating of printed solution (thermal DOD inkjet) or physical deformation of nozzle (piezoelectric DOD inkjet) to print droplets. ${ }^{9}$ During printing, the formation of stable droplets of Newtonian fluids depends on the delicate balance between inertial, viscous, and capillary forces. Conversely, the formation of stable droplets of viscoelastic fluids depends on the delicate balance between inertial, viscous, elastic, and capillary forces. ${ }^{10}$

Unfortunately, an operating map of printable concentrations of surfacntant-free protein solutions with DOD inkjet printing is yet to be determined. ${ }^{1,3,72-74}$ Based on previously published studies, ${ }^{9,75,76}$ such a map (which is presented in Fig.13) was constructed in this study for idenifying the concentrations of surfactant-free protein solutions that are potentially printable with DOD inkjet printing. The map was constructed with dimensionless parameters representing fluid properties of protein solutions such as Ohnesorge $(\mathrm{Oh})$, Weber (We), and Reynolds $(\mathrm{Re})$ numbers:

$$
\begin{gathered}
O h=\frac{\sqrt{W e}}{R e}=\frac{\eta}{\sqrt{\gamma \rho L}}=\frac{1}{Z} \\
W e=\frac{\rho U^{2} L}{\gamma} \\
R e=\frac{\rho U L}{\eta}
\end{gathered}
$$

where $\gamma$ is the surface tension of printed solution, $U$ is the velocity of the droplets, and $L$ is the characteristic length, which is diameter of the orifice in this study. Generally, the nozzle orifice diameter $L$ is between 10 and $120 \mu \mathrm{m}$ and the droplet velocity $U$ is between 1 and $10 \mathrm{~ms}^{-1}$ during DOD inkjet printing. ${ }^{71}$ Accordingly, a mean droplet velocity of $5 \mathrm{~ms}^{-1}$ was chosen for evaluating 
the dimensionless parameters. At the same time, the minimum theoretical droplet velocity $\left(U_{\min }\right.$, required for propelling the droplets) was evaluated with the following relationship: ${ }^{77}$

$$
U_{\min }=\sqrt{\frac{4 \gamma}{\rho L}}
$$

and the corresponding value of the Weber number, which is required for droplet ejection, was determined as $W e>4$. Among previous studies, Jang et al. ${ }^{75}$ investigated the formation of stable droplets during DOD inkjet printing of Newtonian fluids with the inverse Ohnesorge number $Z$. When $Z<4$, the acoustic pressure wave does not have sufficient inertia/kinetic energy to overcome the viscous friction in nozzle and surface tension at the orifice to eject droplets. Conversely, when $Z>14$, the kinetic energy is too large and/or the capillary pressure during droplet breakup is dominant and multiple satellite droplets are ejected along with a primary droplet. Further, Mundo et al..$^{76}$ investigated the onset of splashing of the impacting Newtonian fluids on a flat surface with the splash parameter $\left(K_{s p}\right)$ :

$$
K_{s p}=\sqrt{W e \sqrt{R e}}
$$

The splash parameter $K_{s p}$ depends on the surface roughness, which for flat-smooth surfaces is 57.7, according to those authors. In addition, when $K_{s p}<57.7$, impacting droplets do not splash on a smooth surface. When $K_{s p}>57.7$, the impacting droplets splash on a smooth surface. 


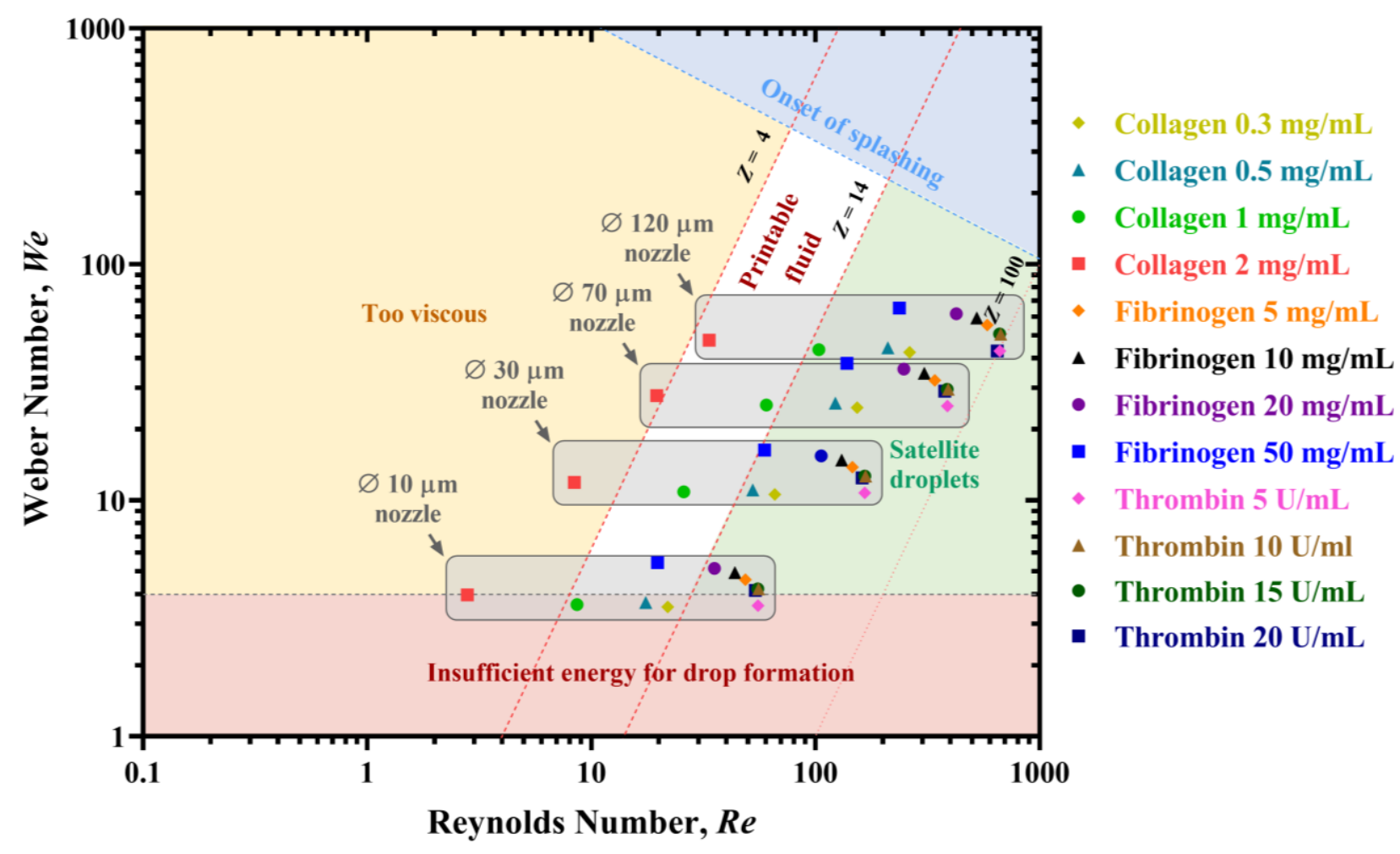

Fig. 13 Map of potentially printable surfactant-free protein solutions with the DOD inkjet printing constructed with dimensionless numbers representing fluid properties of those solutions, drawn following the schematic of Derby et al. ${ }^{9}$ The dimensionless numbers were calculated with the viscosity values of surfactant-free protein solutions measured with Ubbelohde viscometer with the exception of collagen solutions. Zero-shear viscosity values of surfactant-free collagen solutions were assumed same as those of surfactant-laden solutions measured with cone-and-plate rheometer and were used for calculating their dimensionless numbers. In addition, a droplet velocity of $5 \mathrm{~ms}^{-}$ ${ }^{1}$ was chosen for calculating the dimensionless numbers.

According to Fig. 13 (and ESI $\uparrow$ Fig. SI. 5, see ESI $\uparrow$ Tables SI $4-6$ for values of $\gamma$ and $\rho$ and $R e, W e$, and $O h$ numbers), surfactant-free collagen solutions with concentrations between 1 and $2 \mathrm{mg} / \mathrm{mL}$, corresponding to a reduced concentration $\left(c / c^{*}\right)$ between 2 and 4 and a zero-shear viscosity $\eta_{0}$ between 5 and $16 \mathrm{mPa} . \mathrm{s}\left(c^{*}\right.$ and $\eta_{0}$ values of surfactant-free solutions were assumed same as those of surfactant-laden solutions), form stable droplets with an inkjet nozzle having an 
orifice diameter of $90-120 \mu \mathrm{m}$. Similarly, surfactant-free fibrinogen solutions with concentrations between 20 and $50 \mathrm{mg} / \mathrm{mL}$, corresponding to a $c / c *$ between 0.5 and 1.3 and a viscosity $\eta$ between 1.3 and $2.5 \mathrm{mPa} . \mathrm{s}$, form stable droplets with a nozzle having an orifice diameter of $10 \mu \mathrm{m}$. Also, collagen solutions with concentrations between 0.5 and $1 \mathrm{mg} / \mathrm{mL}$, which correspond to a $c / c^{*}$ between 1 and 2 and a zero-shear viscosity $\eta_{0}$ between 3 and $6 \mathrm{mPa} . \mathrm{s}$, form stable droplets with a nozzle having an orifice diameter ranging from 20 to $90 \mu \mathrm{m}$. Conversely, the surfactant-free fibrinogen solutions with $c \leq 20 \mathrm{mg} / \mathrm{mL}\left(c / c^{*} \leq 0.5\right.$ and $\left.\eta<1.4 \mathrm{mPa} . \mathrm{s}\right)$ and surfactant-free thrombin solutions with $c \leq 20 \mathrm{U} / \mathrm{mL}\left(c / c^{*}<<1\right.$ and $\left.\eta \approx 1 \mathrm{mPa} . \mathrm{s}\right)$ form multiple satellite droplets regardless of the orifice diameter. However, a dilute fluid such as water with $Z \approx 100$, was previously shown to form stable droplets with DOD inkjet printing with a frequency $\leq 200 \mathrm{~Hz}^{78,79} \mathrm{Hence}$, it is possible to form stable droplets with those fibrinogen and thrombin solutions with a frequency $\leq$ $200 \mathrm{~Hz}$. Furthermore, impacting droplets of collagen, fibrinogen, and thrombin protein solutions do not splash a smooth surface.

Because polysorbate 80 does not significantly alter the rheology of protein solutions, the surfactant-free semidilute unentangled collagen solutions with c between 1 and $2 \mathrm{mg} / \mathrm{mL}(1.4<$ $\left.\mathrm{c} / c^{*}<2.8\right)$ and surfactant-free fibrinogen solutions with $\mathrm{c} \geq 50 \mathrm{mg} / \mathrm{mL}\left(\mathrm{c} / c^{*} \geq 1.3 \mathrm{mg} / \mathrm{mL}\right)$ solutions are viscoelastic according to Fig. 9. The relaxation times of polymer chains obtained from extensional rheology measurements are often several times larger than those obtained from shear rheology measurements. ${ }^{80,81}$ As a result, viscoelasticity arising because of stretching of protein chains during capillary pinching (of ligament or fluid column/finger that is projected out of the orifice) may become important for those viscoelastic semidilute unentangled protein solutions and prevent the breakup of droplets. ${ }^{82}$ Although proteins adsorb and aggregate at the air/water interface, the mean shear rate experienced during the formation of droplets is as high as 
$5 \times 10^{4} \mathrm{~s}^{-1}$ according Saunders et al. ${ }^{83}$ Accordingly, the influence of the viscoelastic protein film on the capillary pinching is very insignificant. However, protein aggregates can desorb from the air/water interface because of mechanical disturbances and cause further aggregation in the bulk. ${ }^{20,21}$ The acoustic pressure wave (which propels droplets from the nozzle) can also damage proteins and cause further aggregation in the bulk. ${ }^{84}$ The bulk aggregates can entrap air bubbles and disrupt printing. ${ }^{85}$ As a result, experimental DOD inkjet printing studies are further required for validating the general printability map presented in Fig. 13.

\section{Conclusions}

Fibrous collagen and fibrinogen proteins adsorb and aggregate at the air/water interface, forming a viscoelastic solid film that creates and apparent yield stress in those protein solutions when measured in rotational rheometers with an air/water interface. This was probed through interfacial rheology measurements. The viscoelastic film corrupts the bulk rheology measurements with conventional rotational rheometers, such as a cone-and-plate rheometer. However, a non-ionic surfactant, such as polysorbate 80 when added in very small amounts between 0.001 and $0.1 \mathrm{v} / \mathrm{v} \%$ to the protein solutions, prevents the formation of a viscoelastic film at the solution/air interface, allowing the estimation of the true bulk rheology of those solutions.

The yield stress increases with concentration for collagen and thrombin solutions. Contrastingly, the yield stress does not increase with concentration for fibrinogen solutions. This signifies the dependence of interfacial protein film properties on individual monomer properties. The amount of polysorbate 80 required to prevent the yield stress does not increase with concentration for collagen and thrombin solutions. Contrastingly, the amount of polysorbate 80 required to prevent the yield stress increases with concentration for fibrinogen solutions. This 
reflects the absence (collagen and thrombin) or presence (fibrinogen) of binding interactions between the protein monomers and the surfactant molecules.

A general operating map was generated with the viscosity measurements to identify the surfactant-free protein solutions that are printable with DOD inkjet printing. Dilute and semidilute unentangled collagen solutions with concentrations between 0.5 and $2 \mathrm{mg} / \mathrm{mL}$ are predicted to form stable droplets according to the map. Similarly, dilute and semidilute unentangled fibrinogen solutions with concentrations between 20 and $50 \mathrm{mg} / \mathrm{mL}$ are predicted to form stable droplets. Conversely, dilute fibrinogen solutions with concentrations between 5 and $20 \mathrm{mg} / \mathrm{mL}$ and dilute thrombin solutions with concentrations between 5 and $20 \mathrm{U} / \mathrm{ml}$ are predicted to form multiple satellite droplets. However, it is possible to form stable droplets with those dilute solutions using a low frequency between 20 and $200 \mathrm{~Hz}$ as demonstrated previously by DOD inkjet of water. In view of these results, the operating map provides a reference or a starting point for selecting appropriate protein concentrations, inkjet nozzle orifice diameter, and frequency to produce stable droplets during DOD inkjet printing of the surfactant-free collagen, fibrinogen, and thrombin solutions.

\section{Acknowledgements}

This research has been partially supported by the Osteology Foundation Award \#15-042 and the Hartz Career Development Professorship (I.T.O.). The authors thank Aijie Han from the Department of Materials Science and Engineering at Penn State for performing Ubbelohde capillary viscometry measurements for fibrinogen and thrombin protein solutions.

\section{References}

1 E. . Roth, T. Xu, M. Das, C. Gregory, J. . Hickman and T. Boland, Biomaterials, 2004, 25, 
$3707-3715$.

2 Y. B. Lee, S. Polio, W. Lee, G. Dai, L. Menon, R. S. Carroll and S. Yoo, Exp. Neurol., 2010, 223, 645-52.

3 M. Yanez, J. Rincon, A. Dones, C. De Maria, R. Gonzales and T. Boland, Tissue Eng. Part A, 2015, 21, 224-233.

4 V. K. Lee, A. M. Lanzi, H. Ngo, S.-S. Yoo, P. A. Vincent and G. Dai, Cell. Mol. Bioeng., 2014, 7, 460-472.

5 T. Xu, K. W. Binder, M. Z. Albanna, D. Dice, W. Zhao, J. J. Yoo and A. Atala, Biofabrication, 2012, 5, 015001.

6 M. W. Mosesson, K. R. Siebenlist and D. A. Meh, Ann. N. Y. Acad. Sci., 2006, 936, 1130.

7 A. C. Brown and T. H. Barker, Acta Biomater., 2014, 10, 1502-1514.

$8 \quad$ J. Stringer and B. Derby, J. Eur. Ceram. Soc., 2009, 29, 913-918.

9 B. Derby, Annu. Rev. Mater. Res., 2010, 40, 395-414.

10 C. Xu, Z. Zhang, J. Fu and Y. Huang, Langmuir, 2017, 33, 5037-5045.

11 A. Rozhkov, B. Prunet-Foch and M. Vignes-Adler, J. Nonnewton. Fluid Mech., 2006, $134,44-55$.

12 M. Rubinstein and R. H. Colby, Polymer Physics, OUP Oxford, New York, NY, 2003.

13 V. Sharma, A. Jaishankar, Y. Wang and G. H. McKinley, Soft Matter, 2011, 7, 5150.

14 M. M. Castellanos, J. A. Pathak and R. H. Colby, Soft Matter, 2014, 10, 122-131. 
15 J. H. Gu, R. Qian, R. Chou, P. V. Bondarenko and M. Goldenberg, Pharm. Res., 2018, 35, 157.

16 J. Li, M. E. Krause, X. Chen, Y. Cheng, W. Dai, J. J. Hill, M. Huang, S. Jordan, D.

LaCasse, L. Narhi, E. Shalaev, I. C. Shieh, J. C. Thomas, R. Tu, S. Zheng and L. Zhu, AAPS J., 2019, 21, 44.

17 E. Y. Chi, S. Krishnan, T. W. Randolph and J. F. Carpenter, Pharm. Res., 2003, 20, 13251336.

18 W. Wang, Int. J. Pharm., 2005, 289, 1-30.

19 W. Wang, S. Nema and D. Teagarden, Int. J. Pharm., 2010, 390, 89-99.

20 S. Kiese, A. Papppenberger, W. Friess and H. Mahler, J. Pharm. Sci., 2008, 97, 43474366.

21 S. Rudiuk, L. Cohen-Tannoudji, S. Huille and C. Tribet, Soft Matter, 2012, 8, 2651.

22 M. M. Castellanos, J. A. Pathak, W. Leach, S. M. Bishop and R. H. Colby, Biophys. J., 2014, 107, 469-476.

23 E. M. Moussa, J. P. Panchal, B. S. Moorthy, J. S. Blum, M. K. Joubert, L. O. Narhi and E. M. Topp, J. Pharm. Sci., 2016, 105, 417-430.

24 J. A. Paten, S. M. Siadat, M. E. Susilo, E. N. Ismail, J. L. Stoner, J. P. Rothstein and J. W. Ruberti, ACS Nano, 2016, 10, 5027-5040.

25 F. Gobeaux, E. Belamie, G. Mosser, P. Davidson and S. Asnacios, Soft Matter, 2010, 6, 3769. 
26 E. M. Hernández and E. I. Franses, Colloids Surfaces A Physicochem. Eng. Asp., 2003, 214, 249-262.

27 F. S. Ariola, A. Krishnan and E. A. Vogler, Biomaterials, 2006, 27, 3404-3412.

28 H. L. Kim, A. Mcauley, B. Livesay, W. D. Gray and J. Mcguire, J. Pharm. Sci., 2014, 103, 1043-1049.

29 C. Hoffmann, A. Blume, I. Miller and P. Garidel, Eur. Biophys. J., 2009, 38, 557-568.

30 P. Garidel, C. Hoffmann and A. Blume, Biophys. Chem., 2009, 143, 70-78.

31 T. A. Khan, H.-C. Mahler and R. S. K. Kishore, Eur. J. Pharm. Biopharm., 2015, 97, 6067.

32 K. Szymczyk and A. Taraba, J. Therm. Anal. Calorim., 2016, 126, 315-326.

33 N. Rajan, J. Habermehl, M.-F. Coté, C. J. Doillon and D. Mantovani, Nat. Protoc., 2006, 1, 2753-2758.

34 K. K. Moncal, V. Ozbolat, P. Datta, D. N. Heo and I. T. Ozbolat, J. Mater. Sci. Mater. Med., 2019, 30, 55.

35 R. Usha and T. Ramasami, J. Appl. Polym. Sci., 2000, 75, 1577-1584.

36 R. F. Doolittle, J. Thromb. Haemost., 2003, 1, 1559-1565.

37 M. W. Mosesson, J. Thromb. Haemost., 2005, 3, 1894-1904.

38 A. Bratek-Skicki, P. Żeliszewska and J. M. Ruso, Soft Matter, 2016, 12, 8639-8653.

39 C. C. Heuck, U. Schiele, D. Horn, D. Fronda and E. Ritz, J. Biol. Chem., 1985, 260, 4598-603. 
40 E. Leikina, M. V. Mertts, N. Kuznetsova and S. Leikin, Proc. Natl. Acad. Sci., 2002, 99, $1314-1318$.

41 Y. Sun, Z. Luo, A. Fertala and K. An, Biochem. Biophys. Res. Commun., 2002, 295, 382386.

42 S.-W. Chang and M. J. Buehler, Mater. Today, 2014, 17, 70-76.

43 R. D. Averett, B. Menn, E. H. Lee, C. C. Helms, T. Barker and M. Guthold, Biophys. J., 2012, 103, 1537-1544.

44 L. J. Berliner, Thrombin, Springer US, Boston, MA, 1992.

45 TWEEN@ 80 viscous liquid | Polyoxyethylenesorbitan monooleate, https://www.sigmaaldrich.com/catalog/product/sial/p1754.

46 S. Vandebril, A. Franck, G. G. Fuller, P. Moldenaers and J. Vermant, Rheol. Acta, 2010, 49, 131-144.

47 M. L. Huggins, J. Am. Chem. Soc., 1942, 64, 2716-2718.

48 S. Yadav, S. J. Shire and D. S. Kalonia, J. Pharm. Sci., 2010, 99, 4812-4829.

49 E. O. Kraemer, Ind. Eng. Chem., 1938, 30, 1200-1203.

50 S. E. Harding, Prog. Biophys. Mol. Biol., 1997, 68, 207-62.

51 S. Shulman, J. Am. Chem. Soc., 1953, 75, 5846-5852.

52 W. Graessley, Polymer (Guildf)., 1980, 21, 258-262.

53 E. C. Bingham, Bull. Bur. Stand., 1916, 13, 309. 
54 D. T. N. Chen, Q. Wen, P. A. Janmey, J. C. Crocker and A. G. Yodh, Annu. Rev. Condens. Matter Phys., 2010, 1, 301-322.

55 N. Casson, in Rheology of Disperse Systems, Pergamon Press, Oxford, 1959, pp. 84-102.

56 R. Byron Bird and P. J. Carreau, Chem. Eng. Sci., 1968, 23, 427-434.

57 P. J. Carreau, I. F. MacDonald and R. B. Bird, Chem. Eng. Sci., 1968, 23, 901-911.

58 L. Gasperini, J. F. Mano and R. L. Reis, J. R. Soc. Interface, 2014, 11, 20140817.

59 W. Kulicke and C. Clasen, Viscosimetry of Polymers and Polyelectrolytes, Springer Berlin Heidelberg, Berlin, Heidelberg, 2004.

60 T. Nishihara and P. Doty, Proc. Natl. Acad. Sci., 1958, 44, 411-417.

61 Shear Rate Data - 549, https://www.cannoninstrument.com/en/Image/GetDocument/549, (accessed 6 February 2020).

62 M. Brennan and P. F. Davison, Biopolymers, 1981, 20, 2195-2202.

63 D. H. Berry and W. B. Russel, J. Fluid Mech., 1987, 180, 475.

64 ASTM Int., 19AD, 12, 1-26.

65 M. Pierobon, C. Belluco, L. A. Liotta and E. F. Petricoin, in Methods in Molecular Biology, 2011, vol. 785, pp. 3-12.

66 M. Montenegro-Nicolini, V. Miranda and J. O. Morales, AAPS J., 2017, 19, 234-243.

67 Á. Sierra-Sánchez, D. Garrido-Martín, L. Lourido, M. González-González, P. Díez, C. Ruiz-Romero, R. Sjöber, C. Droste, J. De Las Rivas, P. Nilsson, F. Blanco and M. Fuentes, J. Proteome Res., 2017, 16, 1890-1899. 
68 P. B. Identification, M. Harel and T. Geiger, Serum/Plasma Proteomics, Springer New York, New York, NY, 2017, vol. 1619.

69 W. J. Armitage and P. Mazur, Am. J. Physiol. Physiol., 1984, 247, C382-C389.

70 J. P. Wiebe and C. J. Dinsdale, Life Sci., 1991, 48, 1511-7.

71 B. Derby, J. Mater. Chem., 2008, 18, 5717.

72 X. Cui and T. Boland, Biomaterials, 2009, 30, 6221-6227.

73 N. E. Sanjana and S. B. Fuller, J. Neurosci. Methods, 2004, 136, 151-163.

74 A. Zarowna-Dabrowska, E. O. McKenna, M. E. Schutte, A. Glidle, L. Chen, C. CuestasAyllon, D. Marshall, A. Pitt, M. D. Dawson, E. Gu, J. M. Cooper and H. Yin, Colloids Surfaces B Biointerfaces, 2012, 89, 126-132.

75 D. Jang, D. Kim and J. Moon, Langmuir, 2009, 25, 2629-2635.

76 C. Mundo, M. Sommerfeld and C. Tropea, Int. J. Multiph. Flow, 1995, 21, 151-173.

77 P. C. Duineveld, M. M. de Kok, M. Buechel, A. Sempel, K. A. H. Mutsaers, P. van de Weijer, I. G. J. Camps, T. van de Biggelaar, J. Rubingh and E. I. Haskal, in Proceedings of SPIE, ed. Z. H. Kafafi, 2002, p. 59.

78 H. Dong, W. W. Carr and J. F. Morris, Phys. Fluids, 2006, 18, 072102.

79 P. Shin, J. Sung and M. H. Lee, Microelectron. Reliab., 2011, 51, 797-804.

80 R. F. Liang and M. R. Mackley, J. Nonnewton. Fluid Mech., 1994, 52, 387-405.

81 S. L. Anna and G. H. McKinley, J. Rheol. (N. Y. N. Y)., 2001, 45, 115-138. 
82 C. L. Herran and N. Coutris, Exp. Fluids, 2013, 54, 1548.

83 R. E. Saunders, J. E. Gough and B. Derby, Biomaterials, 2008, 29, 193-203.

84 G. M. Nishioka, A. A. Markey and C. K. Holloway, J. Am. Chem. Soc., 2004, 126, $16320-16321$.

85 J. de Jong, G. de Bruin, H. Reinten, M. van den Berg, H. Wijshoff, M. Versluis and D. Lohse, J. Acoust. Soc. Am., 2006, 120, 1257-1265. 